OPEN ACCESS

Edited by:

Nada Rotovnik Kozjek, Institute of Oncology

Ljubljana, Slovenia

Reviewed by:

Donald Ingram,

Pennington Biomedical Research

Center, United States

Dario Coletti,

Sapienza University of Rome, Italy

*Correspondence:

Sebastian J. Hofer

sebastian.hofer@uni-graz.at

Specialty section:

This article was submitted to

Clinical Nutrition,

a section of the journal

Frontiers in Nutrition

Received: 30 May 2021 Accepted: 13 August 2021 Published: 06 September 2021

Citation:

Hofer SJ, Davinelli S, Bergmann M, Scapagnini $G$ and Madeo F (2021)

Caloric Restriction Mimetics in

Nutrition and Clinical Trials.

Front. Nutr. 8:717343.

doi: $10.3389 /$ fnut.2021.717343

\section{Caloric Restriction Mimetics in Nutrition and Clinical Trials}

\author{
Sebastian J. Hofer ${ }^{1,2,3 *}$, Sergio Davinelli ${ }^{4}$, Martina Bergmann ${ }^{1}$, Giovanni Scapagnini ${ }^{4}$ and \\ Frank Madeo ${ }^{1,2,3}$
}

${ }^{1}$ Institute of Molecular Biosciences, NAWI Graz, University of Graz, Graz, Austria, ${ }^{2}$ BioTechMed-Graz, Graz, Austria, ${ }^{3}$ Field of Excellence BioHealth, University of Graz, Graz, Austria, ${ }^{4}$ Department of Medicine and Health Sciences "V. Tiberio", University of Molise, Campobasso, Italy

The human diet and dietary patterns are closely linked to the health status. High-calorie Western-style diets have increasingly come under scrutiny as their caloric load and composition contribute to the development of non-communicable diseases, such as diabetes, cancer, obesity, and cardiovascular disorders. On the other hand, caloriereduced and health-promoting diets have shown promising results in maintaining health and reducing disease burden throughout aging. More recently, pharmacological Caloric Restriction Mimetics (CRMs) have gained interest of the public and scientific community as promising candidates that mimic some of the myriad of effects induced by caloric restriction. Importantly, many of the CRM candidates activate autophagy, prolong life- and healthspan in model organisms and ameliorate diverse disease symptoms without the need to cut calories. Among others, glycolytic inhibitors (e.g., D-allulose, D-glucosamine), hydroxycitric acid, $\mathrm{NAD}^{+}$precursors, polyamines (e.g., spermidine), polyphenols (e.g., resveratrol, dimethoxychalcones, curcumin, EGCG, quercetin) and salicylic acid qualify as CRM candidates, which are naturally available via foods and beverages. However, it is yet unclear how these bioactive substances contribute to the benefits of healthy diets. In this review, we thus discuss dietary sources, availability and intake levels of dietary CRMs. Finally, since translational research on CRMs has entered the clinical stage, we provide a summary of their effects in clinical trials.

Keywords: caloric restriction mimetics, nutrition, spermidine, clinical trials, polyphenols, polyamines, healthy diet

\section{INTRODUCTION}

In addition to genetic, environmental and lifestyle factors, nutrition plays a vital role in shaping health throughout human aging $(1,2)$. Recently, health was defined as the sum of several hallmarks, including, the ability to react to environmental and cellular stress, integrity of barriers and maintenance of cellular and organismal homeostasis (3), of which many cross-talk with dietary factors. In opposition to health, diseases are more described and defined and nutrition takes a central part in these processes as well, prominently in type 2 diabetes, malnutrition-caused diseases, eating disorders, obesity, chronic inflammation and undernutrition, among others (1).

While a moderate consensus has been reached on what defines an unhealthy diet, the constitution of a healthy diet remains debated and subject to different beliefs (4). In principle, healthy diets should have positive effects on diverse health parameters, while not evoking negative effects $(1,4-6)$. Different concepts of healthy dietary plans, including the Healthy Eating Index2010 (HEI-2010), Dietary Approaches to Stop Hypertension (DASH), Alternative Healthy Eating 
Index-2010 (AHEI-2010) and the alternate Mediterranean Diet (aMED) have been developed. These indices estimate and rate the intake of 8-12 components (for instance whole grain, nuts, legumes, fruit, vegetable, alcohol, etc.) and good scores are linked to lower cardiovascular disease (CVD) incidence and cancer mortality (2). In comparison to a Western diet, which is high in processed meat, salt, sugar, saturated fat and low in fresh plant-derived ingredients, these health-optimized diets are richer in plant-based food (fruits, vegetables, whole grains, nuts, and legumes), unprocessed meal components and restricted in animal-based foods (focusing on processed and red meat) (1). The famous Mediterranean diet, which comes in different variations, is roughly composed of daily servings of olive oil, vegetables, fruits, cereals, moderate amounts of fish, meat and sweets and represents one form of a healthy diet which is linked to general health promotion (7-9). In agreement, meta analyses suggest that diets preferring non-hydrogenated unsaturated fats, whole grains, lots of vegetables and fruits are efficient measures against coronary heart disease (10). Given the average Western diet, it thus comes unsurprising that half of cardiovascular and type 2 diabetes related deaths are attributed to unhealthy dietary habits in the United States (11).

Accumulating evidence suggests that caloric restriction (CR) and various forms of fasting (intermittent fasting, time restricted eating, periodic fasting), avoiding malnutrition and including an adequate intake of macro- and micronutrients, present yet additional possibilities to promote the health status by reducing CVDs and cancer, among other beneficial effects (12-14).

Recently, the concept of caloric restriction mimetics (CRMs) was developed to describe pharmacologically active substances that mimic some of CR's myriads of effects (15-20). At the core of the CRM definition, we and others argue that potential CR-mimicking compounds should in principle increase lifeand/or healthspan and ameliorate age-associated diseases in model organisms, thus often the simultaneous use of the term "anti-aging substances." Additionally, CRMs should be capable of inducing autophagy, a homeostasis-regulating cellular recycling mechanisms that degrades obsolete, damaged or otherwise unneeded proteins, cellular structures or organelles $(20,21)$, as well as reducing the acetylation status of proteins (e.g., via activation of deacetylases, inhibition of acetylases or depletion of acetyl-CoA) (22-24). The most physiological inducer of autophagy is nutrient and energy deprivation, such as $\mathrm{CR}$ and fasting. Genetic and pharmacological induction of autophagy can prolong lifespan in various model organisms, counteract neurodegenerative, cardiovascular diseases, various types of cancer and delay the onset of frailty during aging, among others $(21,25-28)$. Autophagy naturally declines during aging and diminished autophagic capacity can contribute to progressive age-associated deteriorations and is implicated in neurodegenerative as well as cardiovascular diseases (29-32). Further denominators of CRMs include the capabilities to mimic more general metabolic, physiological, and hormonal alterations induced by CR, activation of stress response pathways and increased stress resilience (17). Different selections of these criteria are used to define CRMs in literature and, due to the rapidly evolving nature of the field and the broad effects attributed to CR, multiple definitions may exist in parallel. Several chemically diverse CRM candidates have been identified and possible sources span multiple different areas and chemical classes, such as glycolysis inhibitors, inhibitors of fat and carbohydrate metabolism, mTOR inhibitors, AMPK activators, sirtuin activators, polyamines and polyphenols, among others.

While CR and fasting are approaching clinical settings, experimental CRM candidates are rare in clinical research. Given the psychologic limitations of $\mathrm{CR}$ and fasting applications in humans, these compounds hold promise for medical use. A majority of nutrition research has focused on macronutrient composition, food additives, dietary habits or specific food items, as well as their level of industrial processing. The contribution of single dietary compounds to health outcomes is often elusive and understanding the effects of single dietary compounds on health is crucial for determining optimal diets for individual purposes. Ample reviews have been published on different aspects of the CRM concept [e.g., (15-20, 33-36)]. However, the role of naturally occurring CRM candidates in nutrition has been largely overlooked. Hence, in this review we describe these naturally occurring substances that harbor CR-mimicking and anti-aging properties, focusing on their dietary sources, availability and intake levels (Table 1). Several studies suggest that enhanced dietary intake of these substances elicits beneficial effects on human health throughout aging and reduces the incidence of ageassociated diseases (Figure 1). Thus, we summarize the current status of CRMs in nutritional research and clinical trials.

\section{GLYCOLYSIS INHIBITORS}

Early on, CRM candidates were suspected among inhibitors of glycolysis, as an obvious substance class to study for potential CR-mimicking properties. Several compounds have been identified that prolong life/healthspan of model organisms and/or recapitulate other aspects of $\mathrm{CR}$ by inhibiting or modulating enzymes of the glycolysis pathway (e.g., hexokinase). Glycolysis inhibitors are comprehensively studied in cancer research, given many cancer types' increased dependence on glycolysis, but are often incomprehensively studied in nutrition and aging research. Generally, a broader research approach into the effects of these substances is needed to evaluate their potential as CRMs.

D-Allulose (also D-psicose), a rare monosaccharide used as a low-calorie sweetener, inhibits glucose metabolism and absorption from the intestinal tract, intracellular glycolysis and starch and disaccharide metabolization in the intestines. This suggested CRM has multiple pre-clinical effects: importantly, nematodes treated with $\mathrm{D}$-allulose have increased lifespan, mediated via AMPK (78), while its effects on autophagy remain elusive. It is mainly studied for its antihyperglycemic and antiobesity effects (79). D-allulose is naturally present in foods, though at very low concentrations, and has been found in wheat, Itea plants, and processed cane and beet molasses (80). Interestingly, non-enzymatic reactions during heating of products that contain high levels of sugars, such as seasoning sauces and confectionery items, can yield increased, quantifiable 
TABLE 1 | Summary of selected dietarily available compounds with Caloric Restriction Mimetic properties, their estimated intake levels, food sources, and comprehensive literature reviews.

\begin{tabular}{|c|c|c|c|c|}
\hline Class & Compound & $\begin{array}{l}\text { Estimated dietary intake } \\
\text { levels }^{\#+}\end{array}$ & $\begin{array}{l}\text { Relevant dietary } \\
\text { sources }^{+}\end{array}$ & $\begin{array}{l}\text { Relevant articles and } \\
\text { reviews }\end{array}$ \\
\hline \multirow[t]{6}{*}{ Glycolysis inhibitors } & $\begin{array}{l}\text { Astragalin (glucoside form of } \\
\text { kaempferol; also a polyphenol) }\end{array}$ & Unknown & $\begin{array}{l}\text { Various plants, including } \\
\text { Astragalus, Cuscuta } \\
\text { (dodder), Cassia alata }\end{array}$ & $(17,37)$ \\
\hline & D-Allulose (D-psicose) & Unknown & $\begin{array}{l}\text { Wheat, Itea, processed } \\
\text { cane and beet molasses, } \\
\text { high-sugar products (e.g., } \\
\text { seasoning sauces, } \\
\text { especially after heating) }\end{array}$ & $(17,38)$ \\
\hline & $\begin{array}{l}\text { Chrysin (5,7-dihydroxyflavone; also a } \\
\text { polyphenol) }\end{array}$ & Unknown & $\begin{array}{l}\text { Honey, propolis, passion } \\
\text { flowers, mushrooms }\end{array}$ & $(39,40)$ \\
\hline & $\begin{array}{l}\text { Genistein (4',5,7-trihydroxyisoflavone; } \\
\text { also a polyphenol) }\end{array}$ & $\begin{array}{l}2-50 \mathrm{mg} / \text { day (total } \\
\text { isoflavones of which } \\
\text { genistein is a major type) }\end{array}$ & $\begin{array}{l}\text { Various foods, soy-based } \\
\text { items, legumes, fruits, nuts, } \\
\text { vegetables }\end{array}$ & $(41-44)$ \\
\hline & D-Glucosamine & Unknown & $\begin{array}{l}\text { Shellfish shells, cartilage, } \\
\text { fungi }\end{array}$ & $(17,45-47)$ \\
\hline & Mannoheptulose & Unknown & Unripe avocados & $(17,48,49)$ \\
\hline Di/Polyamines & Putrescine, spermidine, spermine & 3-18 mg/day & $\begin{array}{l}\text { Various plant and } \\
\text { animal-based foods, soy } \\
\text { beans, cheese, nuts, seeds, } \\
\text { wheat germs }\end{array}$ & $(50-55)$ \\
\hline \multirow[t]{9}{*}{ Polyphenols } & Total polyphenols & $1 \mathrm{~g} /$ day & Various & $(56-65)$ \\
\hline & $3,4^{\prime}$-dimethoxychalcone & Unknown & *Unknown & \\
\hline & 4,4' -dimethoxychalcone & Unknown & ${ }^{\star}$ Angelica keiskei (ashitaba) & \\
\hline & Curcumin & $29.4 \mathrm{mg} / \mathrm{day}$ & Curcuma longa & \\
\hline & $\begin{array}{l}\text { Flavan-3-ols (e.g., epicatechin, } \\
\text { EGCG) }\end{array}$ & 23-384 mg/day & $\begin{array}{l}\text { Green tea, apples, pears, } \\
\text { berries, cocoa, broad beans }\end{array}$ & \\
\hline & Gallic acid & 25 mg/day & $\begin{array}{l}\text { Berries, citrus fruits, leaf } \\
\text { vegetables, soy products, } \\
\text { tea }\end{array}$ & \\
\hline & Isobacachalcone & Unknown & $\begin{array}{l}{ }^{\star A} \text { Angelica keiskei (ashitaba), } \\
\text { Artocarpus sp. (breadfruit), } \\
\text { Erythrina fusca (purple } \\
\text { coraltree), Morus alba (white } \\
\text { mulberry), Piper longum } \\
\text { (long pepper) }\end{array}$ & \\
\hline & Quercetin & $13.5-29.4 \mathrm{mg} /$ day & Onions, apples, berries & \\
\hline & Resveratrol & $0.1-8 \mathrm{mg} /$ day & $\begin{array}{l}\text { Wines, grapes, lingonberry } \\
\text { and }>100 \text { other plants }\end{array}$ & \\
\hline \multirow[t]{3}{*}{ Others } & Hydroxycitric acid (HCA) & Unknown & Garcinia and Hibiscus & $(66-70)$ \\
\hline & Salicylic acid & $1.3-4.4 \mathrm{mg} /$ day & $\begin{array}{l}\text { Berries, (citrus) fruits, fruit } \\
\text { juices, wines, vegetables } \\
\text { (asparagus, onions) }\end{array}$ & $(71-74)$ \\
\hline & $\mathrm{NAD}^{+}$precursors & $\begin{array}{l}21.9-41 \text { niacin equivalents } \\
(\mathrm{mg}) / \text { day }\end{array}$ & $\begin{array}{l}\text { Various plant and } \\
\text { animal-based foods, } \\
\text { peanuts, nuts, tuna, fish, } \\
\text { pork, beef, soy beans, } \\
\text { cheese, wheat germs }\end{array}$ & $(75-77)$ \\
\hline
\end{tabular}

*Likely present in a variety of polyphenol-rich food items. "Estimated dietary intake levels are subject to profound variations, including different methods of assessment, different dietary habits of study cohorts, large differences of nutritional information in underlying food databases, regional and seasonal variations and diverse food processing techniques. ${ }^{+}$See main text for more details. 


\section{Healthy diets}

- Rich in plant-based food, low in processed meat

- No overconsumption of calories

- Low consumption of sugars, salts and alcohol

- Potential elevated intake of CRMs

- Systemic health benefits

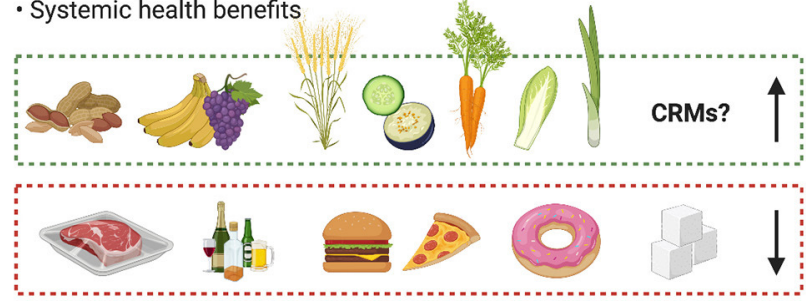

\section{Aging and Westernized Diets}

- Increased cardiovascular disease risk

- Obesity

- Chronic inflammation

- Chronic respiratory diseases

- Increased cancer incidence

- Increased risk for neurological and neurodegenerative diseases

$\cdot \ldots$

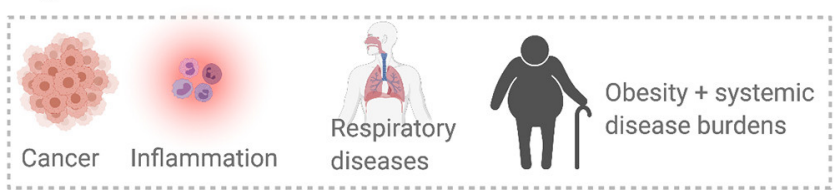

FIGURE 1 | Healthy diet plans stand opposite to Westernized Diets and counteract age-associated deteriorations. The contribution of Caloric Restriction Mimetics (CRMs) to the effects of healthy diets is currently largely undetermined.

levels of D-allulose (e.g., $0.5 \mathrm{mg} / 100 \mathrm{~g}$ in coffee, $130.6 \mathrm{mg} / 100 \mathrm{~g}$ in Worcester sauce) (81).

D-Glucosamine is an amino sugar that serves as a precursor for glycosylated proteins and lipids and acts on glycolysis through hexokinase-1 inhibition. This amino monosaccharide is a CRM candidate due to its lifespan-prolonging effects in nematodes and aging mice $(45,82)$ and its in vivo and in vitro autophagyactivating properties (82-84). In aging mice it was also shown to induce mitochondrial biogenesis, to lower blood glucose levels (45), and to counteract high-fat diet induced metabolic changes in rats (85), thus mimicking several effects of CR. D-glucosamine is naturally occurring, but mainly present in cartilage and shells of shellfish (e.g., shrimp, lobster, crab) where it is present as chitin (a polysaccharide built from $\mathrm{N}$-acetylglucuosamine), which are commercially used for the production of glucosamine dietary supplements. It is also found in fungal cell walls at relatively high levels (86). Similar to D-allulose, the rare occurrence and low levels in commonly used food items prevent estimations of intake levels from normal dietary habits without supplements.

Other glycolysis inhibitors exerting some CR-mimicking effects, which naturally occur in plants and other food items, include, for instance, astragalin, chrysin, genistein, mannoheptulose, and resveratrol. Astragalin is a glucoside form of kaempferol, a bioactive flavonoid, and present in a wide range of plants. Notable plant sources include Astragalus (roots) which has been in medical use in Asia for more than 4,000 years, and Cuscuta (dodder) seeds which are also traditionally used in Asian folk medicine and Cassia alata, among many other plants [reviewed in (37)]. Similarly, chrysin (5,7-dihydroxyflavone) is found in various (medicinal) plants, herbs and fruits and products thereof, including honey [up to $5.3 \mathrm{mg} / \mathrm{kg}$ in forest honey, (87)], propolis [up to $28 \mathrm{~g} / \mathrm{L},(88)$ ], passion flowers (89) and mushrooms at varying levels below $0.5 \mathrm{mg} / \mathrm{kg}(90,91)$, among other sources [reviewed in (40)]. Like other polyphenols, it exerts a wide range of biological activities, but its intake levels from nutrition, stability in food items and bioavailability are poorly understood. Genistein (4',5,7-trihydroxyisoflavone), another phenolic glycolysis inhibitor, belongs to the class of isoflavones and is readily available from diverse food sources, such as soy-based items (mature soy beans contain 5.6 to 276 $\mathrm{mg} / 100 \mathrm{~g}$ ) (92), legumes $(0.2-0.6 \mathrm{mg} / 100 \mathrm{~g})$, fruits, nuts, and vegetables (41). Germination and fermentation of soy beans have been reported to increase genistein content $(93,94)$. Intake of isoflavones (of which genistein is a major type) is estimated to range from 25 to $50 \mathrm{mg}$ /day in Asian countries, while Western countries have much lower intake levels $(\sim 2$ $\mathrm{mg} /$ day) $(95,96)$ (see also chapter on polyphenols). Resveratrol, which is discussed later in the review in more detail, also shows anti-glycolytic activities, as it shows inhibitory effects on hexokinase in cell lines (97). Apart from these phenolic, plantbased compounds, mannoheptulose, a rare sugar, also inhibits hexokinases and was suggested as a CRM which is prominently present in unripe avocados (98), but has produced mixed results in preclinical work (17).

Noteworthy, as an example and prototype for glycolytic inhibitors, 2-Deoxy-D-glucose (2DG) is a well-established and one of the best-known glycolysis inhibitors, acting via its first two enzymatic steps. It was considered one of the first CRM candidates as it lowers body temperature and insulin levels of rats fed a 2DG-containing diet (99), acts cardioprotective, reduces heart rate and blood pressure (100), increases autophagic flux (101), acts as an effective anti-cancer agent (102) and prolongs lifespan, at least in the worm C. elegans (103). However, chronic ingestion has been shown to elicit problematic (cardio)toxic effects in rodents, including increased mortality, and has slowed the transition of 2DG into clinical research $(17,101)$, presenting general challenges for the field. 2DG does not naturally appear in food items and is thus not present in nutritional, epidemiological studies.

\section{Glycolysis Inhibitors in Epidemiological and Clinical Studies}

While several inhibitors of glycolysis are widely present in various food items, their effectiveness in humans, especially via dietary intake, is largely elusive. For most of these substances, clinical studies are absent or insufficient to discuss important topics such as bioavailability, toxicity, metabolization, clinical effects 
and recommended dosages. Nevertheless, for some glycolysis inhibitors data from clinical trials are available.

Upon consumption, D-allulose remains largely unmetabolized and gets secreted to a large extent (104), but seems to reduce glucose uptake from the gut lumen. Few clinical trials (6 interventional trials and 1 meta-analysis registered on clinicaltrials.gov) have investigated the effects and tolerability of D-allulose in humans. One study found decreased glucose levels upon an oral glucose tolerance test (105), matching preclinical reports. This single dose did not change blood glucose levels per se. Likewise, postprandial glucose levels were reduced after pre-meal consumption of $5 \mathrm{~g} \mathrm{D}$-allulose $(106,107)$ and metabolism was shifted toward higher fatty acid oxidation and lower carbohydrate utilization over a day's period (107). A similar study confirmed the notion that the glucose response is dampened upon $\mathrm{D}$-allulose consumption, although the effects did not reach statistical significance (108), while the results on postprandial insulin levels are mixed at the moment. In type-2-diabetes patients, increasing doses of D-allulose also slightly lowered early glucose and insulin levels after an oral sucrose load (109), which is in line with previous reports (110). One randomized clinical trial that lasted for 3 months found favorable reductions in abdominal and subcutaneous fat depots, but no changes in various markers of liver and kidney function, glucose, lipids or insulin (111). However, dosing seems to be crucial for this glycolysis inhibitor, as several side effects, including flatulence, diarrhea and general abdominal discomfort have been reported $(38,112)$. Hayashi and colleagues, however, reported no adverse events or clinical problems in a trial studying the effects of $5 \mathrm{~g} D$-allulose, taken three times a day for 3 months (106). Single doses of up to $0.4 \mathrm{~g} / \mathrm{kg}$ bodyweight and daily consumptions below total $0.9 \mathrm{~g} / \mathrm{kg}$ bodyweight seem to be well-tolerable however (112).

Among the discussed glycolysis inhibitors, glucosamine is one of the most extensively studied compounds in clinical trials. It is commonly used to treat osteoarthritis, as it is a precursor for glycosaminoglycans in cartilage and is widely available as a dietary supplement. An estimated $7.4 \%$ of the US population between 57 and 85 years of age regularly use glucosamine (113) and early prospective studies reported significantly decreased mortality upon regular usage $(114,115)$. This observation is supported by several recent studies in the US $(46,116)$ and the UK $(47)$, which found reduced mortality due to all-causes, CVDs, cancer, respiratory and/or digestive diseases. Besides its potentially mortality-reducing effects in humans, glucosamine has been studied for various reasons in clinical trials, including its anti-inflammatory properties. A 4-weeks long RCT using $1.5 \mathrm{~g} /$ day in combination with $1.2 \mathrm{~g} /$ day chondroitin sulfate (a sulfated type of glucosamine and important structural component of cartilage, which is often sold in combination in supplements) found reductions in CRP (117), which is supported by several pre-clinical studies (118) and epidemiological data (119). Interestingly, regarding its primary reason for application, osteoarthritis, several metaanalyses have been conducted, producing mixed results on its effects for treating symptoms and pain (120-125). Nevertheless, in combination with strong pre-clinical evidence and its good safety profile, ample clinical data speaks for $\mathrm{D}$-glucosamine as a prime CRM candidate with inhibitory functions on glycolysis.

Other glycolytic inhibitors that have been studied in a few clinical trials, include astragalin, chrysin, and genistein. Astragalin, as an isolated compound, is largely absent in clinical literature. However, its non-glucoside form kaempferol has been weakly associated with anti-diabetic and anti-cancer effects (126-128). Likewise, administration of astragalus roots which have high astragalin content (129) has shown antidiabetic effects, lowering fasting glucose and insulin levels, postprandial glucose levels and insulin resistance (130), although the authors of this meta-analysis conclude that some underlying studies lack quality and more rigorous studies of astragalus administration are needed. Chrysin has shown promising results on pre-clinical models of metabolic disorder and cancer (39, 131). It is available as a dietary supplement but shows poor oral bioavailability (132), while not evoking problematic toxic effects at the doses studied (single-dose of 400-500 mg) (132, 133). However, its effects as a potential CRM and glycolysis inhibitor, either from diet or as supplement, remain unknown in humans. Similarly, genistein has been studied for its anticancer properties. It has a bitter taste and is poorly soluble in water with a low bioavailability when consumed orally (41), which might be overcome by encapsulation or using genistin, its glycoside form $(134,135)$. Evidence of genistein's effects in humans is weak, mainly derived from epidemiological studies and smaller interventional trials that often do not differentiate between multiple isoflavones and use mixtures of several compounds (41). Searching clinicaltrials.gov for genistein reveals 72 registered trials and more can be found in literature databases. Several meta-analyses of clinical trials have been conducted for various purposes. For instance, genistein supplementation at 54 $\mathrm{mg} / \mathrm{day}$ is associated with beneficial effects on bone mineral density in postmenopausal women (136), longer durations of supplementation ( $>6$ months) may be associated with reduced blood pressure in patients with metabolic syndrome (42) and increased intake with lower type-2-diabetes (137-139) and reduced breast cancer risk (138). Thus, ample data of its effects in pre-clinical models and humans (either via nutritional assessments or interventional supplementations), suggest this isoflavone as an interesting CRM candidate with inhibitory effects on glycolysis, thus warranting more research and larger RCTs into its potential CR-mimicking properties.

\section{HYDROXYCITRIC ACID}

Hydroxycitric acid (HCA), a derivative of the TCA-cycle metabolite citric acid, is a phytochemical compound that qualifies as a CRM due to its autophagy-stimulating properties (24). Mechanistically, HCA is a competitive inhibitor of ATP-citrate lyase which is involved in lipogenesis. To date it has been reported in two plant species: Garcinia and Hibiscus. More specifically, HCA can be extracted from the fruit rind of Garcinia gummi-gutta, also known as Garcinia cambogia or Malabar Tamarind, Garcinia indica, and Garcinia atroviridis. Garcinia trees are native to India, as well as Africa, Sri Lanka and Malaysia 
(66). The tree produces little green fruits, rich in numerous bioactive phytochemicals, of which HCA is believed to be the major ingredient (67). Garcinia extracts have been mainly studied for anti-inflammatory, -cancer and -obesity effects (66).

Besides Garcinia, HCA is present in Hibiscus sabdariffa (Roselle) and Hibiscus rosa-sinensis (140). Hibiscus plants are endemic in Africa and South-East-Asia. Like Garcinia, Hibiscus plants are used in multiple ways, as food colorings, jams, cold drinks, teas and nearly all parts of the plant (leaves, stems, fruits, flowers) are used for cooking (68).

While numerous HCA-containing garcinia-derived extracts with varying HCA concentrations are sold over-the-counter mainly for weight loss promotion, no information can be found about dietary intake levels of HCA in regions home to Garcinia or Hibiscus.

\section{Hydroxycitric Acid in Epidemiological and Clinical Studies}

Pre-clinical studies of HCA have shown promising results for obesity management, including appetite suppression properties, which is why it is commonly taken for weight management (141), although the effectiveness is questionable. Different doses have been used in human trials, ranging from 5 to $250 \mathrm{mg} / \mathrm{kg}$, or up to $4.7 \mathrm{~g}$, daily HCA supplementation, usually divided into smaller sub-doses taken throughout the day $(67,142)$. Bioavailability is fairly fast after HCA intake and the compound can be detected in human plasma for several hours after acute intake (143). While there are yet no general recommendations for HCA intake, it has been found safe at daily doses up to $3 \mathrm{~g}$ for 30 days, administered in capsules or tablets $(141,144-147)$. Potential adverse events include mild gastrointestinal problems, diarrhea, nausea and flatulence. This warrants further research into side effects of HCA and HCA-containing extracts, focusing on long-term use $(67,148)$.

Several randomized clinical trials (RCTs) were conducted with different HCA-containing formulations which reported inconsistent outcomes on energy intake, weight gain, fat oxidation and appetite reduction (142). This could be partly due to the wide range of concentrations and different study designs used in these studies. Also, HCA occurs in different chemical forms, with the lactone form being a less potent inhibitor of ATP-citrate lyase than the open form (149), which might explain some inconsistencies when using different formulations in clinical trials.

Some clinical trials have shown that it can reduce obesityrelated visceral fat accumulation (150). However, as summarized and discussed in Onakpoya et al., meta-analyses of RCTs using Garcinia extracts for weight loss show only small effects on short term weight loss (69) and the effects of HCA administration in humans remains controversial (142), especially regarding longer term effects. Different types of bowel disorders were treated with the fruit rind of Garcinia $(66,151)$ and pre-clinical work has shown anti-inflammatory properties of HCA (152).

In summary, HCA has shown promising effects in pre-clinical and encouraging, yet little, evidence for its effectiveness in humans. Its contribution to healthy diets remains elusive and its possible application in clinical settings is yet to be studied with more rigor, particularly in the long term.

\section{NAD+ PRECURSORS}

Nicotinic acid (NA, also named niacin or Vitamin B3), nicotinamide (NAM), nicotinamide riboside (NR), nicotinamide mononucleotide (NMN) and tryptophan are all dietarily available precursors of $\mathrm{NAD}^{+}$(nicotinamide adenine dinucleotide) with similar biological activities $(75,76,153)$. The universal coenzyme $\mathrm{NAD}+/ \mathrm{NADH}$ and its phosphorylated derivatives NADP/NADPH serve oxidoreductases, dehydrogenases, sirtuins and are central to metabolic pathways (e.g., glycolysis, TCA cycle) and cell signaling (153). Numerous pre-clinical studies have shown the CRM-like properties of these precursors upon supplementation, which can prolong life- and healthspan, promote mitochondrial function, induce autophagy and act cardioprotective and neuroprotective, among others (77, 153157). $\mathrm{NAD}^{+}$concentrations decline with age $(156,158)$ and replenishing these levels harbors therapeutic potential in humans (157, 159-164).

$\mathrm{NAD}^{+}$precursors are abundantly present in foods of animal and plant origins and $\mathrm{NAD}^{+}$levels can be increased by dietary habits, as well as physical activity/exercise $(75,165)$. Taking into account de novo synthesis from tryptophan (it is commonly estimated that $60 \mathrm{mg}$ of dietary tryptophan can yield $1 \mathrm{mg}$ niacin in the body, although large interindividual variability exists), dietary supply of $\mathrm{NAD}^{+}$precursors is calculated as niacin equivalents (NE) (166). To avoid hypovitaminosis, recommendations for daily $\mathrm{NE}$ intake are 14 to $16 \mathrm{mg}$ (166) and niacin is rapidly absorbed from the gastrointestinal tract (167).

Interestingly, in the Bruneck study situated in northern Italy, recent analysis found relative high dietary NE intake of $28.9 \mathrm{mg}$ (23.5 to 35.0 ) in men and $26.9 \mathrm{mg}$ (21.9 to 33.0 ) in women per day (154), which is corroborated by similar observations made in the US (28 and $18 \mathrm{mg}$ niacin/day for men and women, respectively) and Canada (41 and $28 \mathrm{mg}$ niacin/day for men and women, respectively) (76).

The highest concentrations of $\mathrm{NE}$ can be found in nuts, especially peanuts, $(20,833 \mu \mathrm{g} \mathrm{NE} / 100 \mathrm{~g})$, tuna $(14,383 \mu \mathrm{g}$ $\mathrm{NE} / 100 \mathrm{~g})$, poultry $(12,534 \mu \mathrm{g} \mathrm{NE} / 100 \mathrm{~g})$, beef $(9,235 \mu \mathrm{g}$ $\mathrm{NE} / 100 \mathrm{~g}$ ) pork, lamb, and fish like trouts and salmons (all $>5,000 \mu \mathrm{g} \mathrm{NE} / 100 \mathrm{~g}$ ). Other foods rich in NE are curd and cheese (2,800 and 5,226 $\mu \mathrm{g} \mathrm{NE} / 100 \mathrm{~g}$, respectively), along other dairy products, fruits and vegetables, with wheat germs $(10,020 \mu \mathrm{g}$ $\mathrm{NE} / 100 \mathrm{~g})$, mushrooms $(5,220 \mu \mathrm{g} \mathrm{NE} / 100 \mathrm{~g})$, green peas $(3,621$ $\mu \mathrm{g} \mathrm{NE} / 100 \mathrm{~g})$, garlic $(2,300 \mu \mathrm{g} \mathrm{NE} / 100 \mathrm{~g})$, dried prunes $(1,730 \mu \mathrm{g}$ $\mathrm{NE} / 100 \mathrm{~g})$ and bananas $(1,033 \mu \mathrm{g} \mathrm{NE} / 100 \mathrm{~g})$ ranking among the NE richest items. Potatoes, rice and carbohydrate-based foods, like bread and noodles are also relatively NE-rich $(>1,000 \mu \mathrm{g}$ $\mathrm{NE} / 100 \mathrm{~g}$ ) (154). NMN was also found to be abundantly present in foods like tomatoes $(260-300 \mu \mathrm{g} / 100 \mathrm{~g})$, broccoli $(250-1,120$ $\mu \mathrm{g} / 100 \mathrm{~g}$ ), mushrooms (up to $1,010 \mu \mathrm{g} / 100 \mathrm{~g}$ ), and raw beef (60-420 $\mu \mathrm{g} / 100 \mathrm{~g})(168)$.

Interestingly, pellagra, a niacin- and tryptophan-deficiency caused disease common to rural, southern areas of the US 
a century ago, was cured by substituting mainly corn-based diets with milk, eggs and meat (169). Of note, niacin in corn and mature grain is mainly present in bound forms that are poorly bioavailable. Thus, nixtamalization (soaking and cooking in alkaline solution) is often applied to render hemicellulosebound niacin bioavailable from these sources, a practice that was already used by Native American populations $(75,170)$.

\section{NAD $^{+}$Precursors in Epidemiological and Clinical Studies}

Due to mounting pre-clinical evidence on the beneficial effects of $\mathrm{NAD}^{+}$precursor supplementation and $\mathrm{NAD}^{+}$depletion as a possible contributor to (age-associated) human diseases, research into the clinical feasibility of these substances beyond the treatment of hypovitaminosis has gained traction (77). Querying "niacin," "NAD+," and "nicotinamide" in clinicaltrials.gov results in hundreds of registered trials in diverse clinical settings and cohorts, many of them with dietary supplements.

Toxicity is low and tolerability high in rodents (161) and several academic sponsors and companies are currently running clinical trials on $\mathrm{NAD}^{+}$precursors [for a comprehensive list of completed trials see (77)]. NR, NAM, and other $\mathrm{NAD}^{+}$ precursors are being tested in clinical trials at doses up to $2 \mathrm{~g} /$ day, which overall seem well-tolerable, orally bioavailable and increase blood $\mathrm{NAD}^{+}$levels $(77,171-175)$. One study found reduced circulating inflammatory markers and elevated muscle $\mathrm{NAD}^{+}$ metabolites upon 3 weeks of daily $1 \mathrm{~g}$ NR supplementation (176). The same dose, however, failed to elicit effects on insulin parameters and glucose tolerance after 3 months in non-diabetic obese men (177). Daily supplementation of $500 \mathrm{mg}$ NR with a detectable increase in $\mathrm{NAD}^{+}$serum levels did not cause serious adverse effects after 8 weeks (173). This was corroborated by a 6 week long study supplementing NR, via a commercially available supplement, which also found reduced systolic/diastolic blood pressure and arterial stiffness (178).

Niacin has been used in doses $>1 \mathrm{~g}$ to treat hypercholesterolemia, lowering LDL while raising HDL levels (179). Of note, NAM alone at $1 \mathrm{~g}$ /day also evoked similar changes in the LDL/HDL levels (180). A recent study found increased intramuscular $\mathrm{NAD}+$, muscle strength and mitochondrial biogenesis in patients with mitochondrial myopathy after 10 months of up to $1 \mathrm{~g} /$ day niacin supplementation (181). This was accompanied by a shift in the muscular metabolomes toward those of controls. A case study found amelioration of movement disorders in a patient with Parkinson Disease (PD) upon 1 g/day niacin supplementation (182). However, double the dose eventually led to nightmares and skin rashes, which stopped upon niacin discontinuing, also reinstating the initial severity of movement disorders. Another case report also found improved motor, cognitive and sleep measures after $0.25 \mathrm{~g} /$ day niacin treatment for 1.5 months in a PD patient (183). Interestingly, German PD patients have reportedly lower dietary niacin consumption (184).

As summarized by Katsyuba et al. the sum of clinical trials with $\mathrm{NAD}^{+}$precursors supports the general safety of the compounds at the doses indicated. However, effects on different outcomes vary greatly between the studies (77). As outlined before, $\mathrm{NAD}^{+}$precursors are important dietary components and widely spread in various foods. Analysis of dietary habits from the Bruneck study have shown lower all-cause and cardiovascular mortality risk, alongside lower systolic blood pressure, associated with diets rich in $\mathrm{NAD}^{+}$precursor (154).

\section{POLYAMINES}

The naturally occurring, ubiquitously found polyamines spermidine and spermine have been attributed diverse healthpromoting effects in model organisms and humans [reviewed in detail in $(50,185)]$. Polyamines are available to our bodies via the diet, microbial production in the gut, and endogenous biosynthesis. They serve multiple biological roles, from growth, translation, ion channels and autophagy regulation to binding of nucleic acids and other molecules (186). Externally supplied dietary spermidine evokes cardioprotective and neuroprotective effects in mice, activates autophagy and prolongs life- and healthspan (187-191). Together with precursors (ornithine, arginine, methionine, among others) and the diamine putrescine, these bioactive substances are an unavoidable part of human diets. Additionally, they are synthesized by the gut microbiome, providing an additional polyamine source, and are easily taken up from the gut lumen (51). Several studies have estimated the average intake levels of these compounds across different countries, while variations in microbiota-derived polyamine levels are elusive.

Generally, putrescine seems to make up the greatest share of dietary di/polyamines, both in weight and $\mu$ mol. At the lower end of estimated intake levels stands Turkey with $8 \mathrm{mg}$ putrescine, $5 \mathrm{mg}$ spermidine, and $3 \mathrm{mg}$ spermine per day (192). Asian countries are estimated to have daily intake levels of 9, 13 , and $8.5 \mathrm{mg}$ for putrescine, spermidine and spermine, respectively (193). Countries in the European Union consume $18 \mathrm{mg}$ putrescine, $12.6 \mathrm{mg}$ spermidine, and $11 \mathrm{mg}$ spermine daily on average (52), while the USA report roughly one third lower polyamine consumption levels (194). Due to different dietary habits, great regional variations exist. For instance, while spermidine intake levels in Spain are estimated to be around $15 \mathrm{mg} /$ day, those of Sweden are only $10 \mathrm{mg} /$ day (52). A population-based study in northern Italy, that rigorously assessed the dietary habits via FFQs, came to an estimated intake of $13.4 \mathrm{mg}$ putrescine, $10.1 \mathrm{mg}$ spermidine, and $6.3 \mathrm{mg}$ spermine (195). Interestingly, the same study found a significant trend toward declining spermidine intake levels with age and generally higher dietary consumption in women.

As mentioned, polyamines are ubiquitously present in food items of plant and animal origins. Within food categories, however, wide ranges of concentrations are found, with plantbased food ranking higher on average (52). Thus, it can be speculated that healthy diets as outlined above likely contain elevated polyamine levels. This is corroborated by positive correlations between food items typically consumed in higher quantities in Mediterranean countries and polyamine content (7). A comprehensive summary of polyamine content in various 
food items can be found in Atiya Ali et al. (53). Putrescine is found in high quantities in fruits $(500-550 \mu \mathrm{mol} / \mathrm{kg}$ ), while vegetables and bread contain roughly a tenth of those levels. In contrast, spermidine is more abundant in, particularly aged, cheese $(600-700 \mu \mathrm{mol} / \mathrm{kg})$ and vegetables $(200-300 \mu \mathrm{mol} / \mathrm{kg})$, than in fruits $(100-200 \mu \mathrm{mol} / \mathrm{kg})$, while it's especially low in meat $(<50 \mu \mathrm{mol} / \mathrm{kg})$. Spermine is found in comparable amounts in meat, vegetables and cheese $(100-200 \mu \mathrm{mol} / \mathrm{kg})$, while bread, potatoes and fruits contain $<50 \mu \mathrm{mol} / \mathrm{kg}$ (53). Specific food items rich in polyamines are rice bran, wheat germs, nuts, seeds, green pepper, broccoli and its sprouts, fish sauce, oranges, mangos, chicken liver, beef intestines, some shellfish, select mushrooms, and soybeans (196). Natto, which is based on fermented soy beans, is especially rich in spermidine and has led to polyamine-enriched variants being studied in clinical studies (197). Taking portion sizes and intake frequencies into account, within the Bruneck study, the greatest contributors to spermidine intake were whole-grain, apples, pears, salads and vegetable sprouts (195).

Measured or estimated polyamine content varies greatly between different reports. Thus, epidemiological, fooddatabase dependent data are obviously prone to various confounding factors, including the often unknown influences of regional/seasonal variability or preparation techniques, stability, manufacturing, and storage methods in different food items, just to name a few. This applies as well to the other dietary compounds discussed in this review. Reviewing existing literature revealed substantial knowledge gaps on the influence of the named factors on polyamine content (50). No consistent tendencies are present across different reports. However, literature suggests that while spermidine and total polyamines seem rather stable upon boiling/cooking in most foods, polyamines might get lost into excess cooking liquids and fermentation in principle might favor polyamine abundance $(50,54)$.

\section{Polyamines in Epidemiological and Clinical Studies}

Polyamines have been studied in moderate extent in clinical or epidemiological trials. The "Bruneck study", named after the hospital's location in northern Italy where the study visits were conducted, is a prospective population-based study that rigorously assessed dietary habits and health status, including numerous physiological examinations (198). Polyamine intake data were calculated via dietitian-administered food frequency questionnaires (FFQs) and food databases to correlate intake levels to various health parameters. In this cohort it was observed that cardiovascular diseases (188), cognitive impairment (190), and overall mortality (including cancer and vascular deaths) (195) negatively correlated with higher polyamine intake. These associations were robust to withstand corrections for possibly confounding factors including social status, age, BMI, calorie intake, education, alcohol or nicotine consumption, activity and healthy eating, and were more prominently pronounced for spermidine than spermine (both are enzymatically interconvertible), while putrescine intake levels did not show significant correlations. The inverse correlation of spermidine intake and overall mortality was consequently corroborated by the SAPHIR study (195), while the negative correlation with CVD incidence was confirmed by another epidemiological study (199).

Although polyamines show promising effects in pre-clinical studies and epidemiological data point toward benefits of increased dietary intake, only few interventional clinical trials have been conducted so far. One of them, designed as a pilot trial, supplemented elderly people with low doses of polyamines via a wheat-germ extract ( $1.2 \mathrm{mg}$ spermidine, $0.6 \mathrm{mg} / \mathrm{spermine}, 0.2 \mathrm{mg}$ putrescine per day) for 3 months and found a positive impact on memory performance (200). The same extract was previously found to be safe in mice and older humans, while not provoking changes in vital signs in the latter after 3 months (201). Another study supplemented spermidine via wheat-germ containing bread rolls (3.3 mg spermidine/piece, $\sim 23$ pieces/month) for 3 months to older adults living in nursing homes and found subtle improvements in cognitive function of patients with mild dementia (202).

Recently, spermidine- and spermine-enriched natto was tested in a 1-year-long intervention study, reaching a daily intake increase of roughly $14.5 \mathrm{mg}$ spermidine and $4.5 \mathrm{mg}$ spermine (197). Interestingly, only spermine blood levels rose by $12 \%$ at study end, suggesting either metabolic adaptations in the polyamine pathway or ready tissue uptake and/or metabolization of dietary polyamines. The study showed decreased levels of lymphocyte function-associated antigen 1 (LFA-1) upon elevated polyamine intake (197), suggesting potential anti-inflammatory effects of polyamine supplementation in humans. Interestingly, polyamine modulation cannot only be achieved by direct increase of intake levels, but also via modulation of the polyamineproducing intestinal microbiota. One study administered a yogurt preparation with Bifidobacterium animalis subsp. lactis and arginine (precursor of polyamine synthesis) for 3 months and found higher serum putrescine and spermidine levels, decreased heart rate, as well as improved endothelial function in the intervention group compared to the placebo (normal yogurt) (203). Other in-group significant changes included slightly reduced triglycerides, total cholesterol and platelet counts, while HDL-cholesterol increased (changes not significant in comparison to those in the placebo group).

Due to the increased need for polyamines of cancer cells, there was some concern regarding potential cancer-increasing risk of elevated polyamine intake. While one study found increased risk for colorectal adenoma at above-median intake levels (204), the same group found an inverse relationship for colorectal cancer in a different cohort (205), highlighting the need for multiple observational or direct interventional studies. Additionally, multiple other epidemiological studies, as outlined above, did not observe cancer-increasing effects of elevated polyamine intake, rather the opposite. Other interesting avenues of polyamine supplementation in humans include the potentially supporting effects on hair growth $(206,207)$.

Ongoing or yet-to-be-published trials registered at clinicaltrials.gov, which use dietary spermidine supplementation (4-6 mg/day), include explorative hypothesis-generating 
studies against depression and for sleep quality improvement (NCT04823806), one against hypertension (NCT04405388) and one against cognitive decline in elderly subjects (NCT03094546).

\section{POLYPHENOLS}

Plant compounds belonging to the polyphenol family may represent promising sources of potential CRMs (15). Polyphenols are ubiquitous phytochemicals characterized by great chemical diversity. They represent one of the largest groups of secondary metabolites in plants with over 8,000 structural variants (208). Polyphenols fulfill multiple ecological roles in the plant kingdom, from defense against biotic and abiotic stressors to inter- and intra-kingdom communication. The most common classification used in the literature implies their subdivision in two main groups: flavonoids (e.g., anthocyanins, flavan-3-ols, flavanones, flavonols, flavonones, and isoflavones) and non-flavonoids (e.g., phenolic acids, stilbenes, and lignans) (209). Like polyamines and $\mathrm{NAD}^{+}$precursors, these compounds are an unavoidable component in the human diet.

About 800 different polyphenols have been identified in a wide range of plant foods and beverages, including berries, whole-grain cereals, cacao, coffee, and tea $(210,211)$. Some food and beverages may be particularly rich in a specific polyphenol class; for example, stilbenes in red wine, phenolic acids in coffee, flavanones in citrus fruits, flavanols in cocoa, and isoflavones in soy products (56). It is important to note that polyphenol content is markedly influenced by plant variety, agricultural practices, and food processing methods. All these factors account for the high variability in the polyphenol profile of plant foods and beverages (212). Although it has often been criticized, the translation of food composition into intakes of specific polyphenols is usually achieved using food composition databases, such as Phenol-Explorer or the database of the United States Department of Agriculture (USDA) for flavonoids $(211,213)$. Depending on the type diet, gender and other sociodemographic factors, the average polyphenol intake in the human diet is approximately $1 \mathrm{~g} /$ day $(57,214)$. Estimated intake levels for specific polyphenols from different reports need to be treated especially carefully, as the underlying databases and methods of calculation may vary significantly.

A few prominent examples of polyphenols that may mimic $\mathrm{CR}$ in humans include resveratrol, curcumin, epicatechin, epigallocatechin-3-gallate (EGCG), gallic acid, and quercetin.

The main representative of stilbenes in the human diet is resveratrol. It has been detected in 100 plant species from 35 taxonomic families (215). Estimations of daily resveratrol intake range from 100 to $933 \mu \mathrm{g}$ in a Spanish study (combined resveratrol and piceid, a glucoside derivative) (216) to $6-8 \mathrm{mg}$ (217), mainly coming from wines and grape products (216). According to Phenol-Explorer, lingonberry (Vaccinium vitisidaea) was found to have the highest content of resveratrol [3.00 $\mathrm{mg} / 100 \mathrm{~g}$ fresh weight [FW)] (218). However, the fresh skin of red grapes is also particularly rich in resveratrol, which contributes to its relatively high concentration $(3.02 \mathrm{mg} / 100 \mathrm{ml})$ in red wine from Muscadine grape (219).
Curcumin is a well-known polyphenolic compound isolated from the rhizomes of Curcuma longa (turmeric). The plant is often cultivated to harvest rhizomes and use turmeric powder as a spice and food coloring agent. The average Indian diet provides roughly $60-100 \mathrm{mg}$ per day (58). The contents of curcumin in turmeric rhizomes vary often with varieties, locations, and cultivation conditions. However, by aggregating data from 14 different samples from 3 publications, the average content of curcumin in dried turmeric is $2,213.57 \mathrm{mg} / 100 \mathrm{~g} \mathrm{FW}(220-222)$.

Epicatechin and EGCG belong to the flavan-3-ol subclass of flavonoids. Dietary intake levels of total flavanols were estimated to be $386 \mathrm{mg} /$ day in Germany (223), $192 \mathrm{mg} /$ day in the US (224), and $23 \mathrm{mg}$ /day in the Netherlands (225), highlighting a high discrepancy in the published literature and problems with differences in the underlying food databases and intake estimations. Of the individual flavan-3-ols, epicatechin, and catechin seem to make up most of the dietary intake (68 and $84 \mathrm{mg} /$ day, respectively), in the US (224). Recently, it has been proposed that the estimated intake of flavan-3-ols can only be interpreted as a marker of specific dietary patterns, but not as the actual intake amount (59). Epicatechin is found abundantly in different fruits and legumes, such as apples, pears, berries, cocoa, and broad beans. Likewise, EGCG is the most biologically active and most abundant flavan-3-ol in green tea. Quantitative data on flavan-3-ol contents of foods are largely debated. This is due to the limitations of self-reporting dietary data (e.g., food-frequency questionnaires) and the inability of currently used methods to accurately estimate the high variability of food composition. Rothwell et al. reported that the values of flavan-3-ols ranged from 3 to $544 \mathrm{mg} / 100 \mathrm{~g}$ in apples, chocolate (dark), and green tea $(60)$.

The flavonol quercetin is one of the most extensively studied polyphenols for its anticancer, antiaging, and anti-inflammatory activities. It is mainly found in onions, apples, and berries. Estimated intake levels of quercetin are $29.4 \mathrm{mg} /$ day in the United Kingdom (226), $20 \mathrm{mg} /$ day in the Chinese population (227) and $13.5 \mathrm{mg} /$ day in the US (224). Another example of potential CRMs is gallic acid, which is a well-known polyphenol belonging to the class of phenolic acids. A polish study estimated a daily intake of $25 \mathrm{mg}$ gallic acid (228), which can be found in berries, citrus fruits, leaf vegetables, and soy products and it is known mainly for its antioxidant effect (61). However, tea is also an important source of gallic acid. Data reported in PhenolExplorer indicate that the mean content of gallic acid in black tea infusion is $4.63 \mathrm{mg} / 100 \mathrm{ml}(60)$.

Recently, chalcones have emerged as another specific sub-class of polyphenols that might qualify as CRMs. 3,4dimethoxychalcone and 4,4'-dimethoxychalcone, among other chalcones, were identified in screens of (plant) metabolites to induce autophagy in vivo and prolong health- and/or lifespan of yeast, worms and flies (229-232). 4,4'-dimethoxychalcone was later also shown to ameliorate Parkinson's Disease phenotypes in mice when delivered to neuronal tissue via targeted nanoparticles (233), exemplifying one interesting way of overcoming the in vivo limitations of such small molecules. Isobacachalcone has also been shown to induce autophagy and enhance chemotherapy in mice (234). Chalcones are present in a wide range of plants and 
plant-derived extracts and are thus dietarily available to humans and have been used in traditional medicines across continents.

However, their concentrations in the identified plants are often unknown and no dietary intake levels can be estimated. For instance, isobacachalcone was found in the edible or partly edible plants Angelica keiskei (ashitaba), Artocarpus sp. (breadfruit), Erythrina fusca (purple coraltree), Morus alba (white mulberry), and Piper longum (long pepper), among others, and is attributed multiple health-promoting properties [summarized in (234)]. Of note, 4,4'-dimethoxychalcone was also identified in the chalconerich ashitaba plant (229). Although no specific information can be found about the presence of these chalcones in other food items, chalcones are generally widely present in plant-based food, such as tomatoes, apples and legumes (62).

\section{Polyphenols in Epidemiological and Clinical Studies}

The consumption of polyphenols has been epidemiologically associated with the beneficial modulation of a wide number of health-related variables, including mortality risk $(235,236)$. However, health benefits and CR-like effects of polyphenols are difficult to demonstrate in humans due to the wide variability of chemical structures, biological actions, and complexity of estimating their content in foods and cooked dishes. Bioavailability is another crucial aspect when the effects of polyphenols are evaluated in humans. It has been estimated that circulating concentrations of both native and metabolic forms of polyphenols are in the nanomolar to low micromolar range and, therefore, only a small percentage is detected in urine and plasma samples $(57,63)$. Also, many clinical studies concentrate on polyphenol-rich extracts, juices, or diet plans rather than pure compounds, often with unknown exact compositions. Effects often vary significantly between studies, which can likely be attributed to small cohort sizes, big variations in study design, different doses and cohorts and underlying confounding factors (like pre-study dietary intake).

Although resveratrol mimics some aspects of CR in humans, current clinical trials with resveratrol supplementation and epidemiological studies report promising but mixed findings. The amount of available data would overstrain the purpose of this review and is more comprehensively reviewed elsewhere $(64,217)$.

Tolerability of supplemented doses up to $1 \mathrm{~g}$ seems fairly good (217). The effects of resveratrol supplementation on BW and/or waist circumference (WC) were investigated by 4 studies (237240), of which three found a reduction of WC and two studies detected reduced BW after resveratrol supplementation. Two reports found a reduction of cholesterol levels, while six others did not (237, 241-247). Likewise, 1 study showed that resveratrol can improve triglyceride (TG) in diabetic patients (247).

While three meta-analyses observed no effect on glucose levels after treatment with resveratrol $(238,244,245)$, three studies reported that resveratrol could decrease blood glucose $(237,242$, 248). Four publications also analyzed glucose-related parameters, such as insulin levels and glycated hemoglobin (HbA1c) (238,
$242,243,248)$. The authors of 3 meta-analyses evaluating HbA1c reported that patients may benefit from resveratrol treatment.

During aging, chronic, sterile, low-grade inflammation, called inflammaging, contributes to the onset of age-related diseases (249-252). Overall, meta-analyses found reduced levels of C-reactive protein (CRP) and tumor necrosis factor (TNF) in resveratrol-supplemented individuals but no influence on interleukin 6 (IL-6) $(242,245,253-256)$. In an intervention trial with patients suffering from type 2 diabetes (T2D), CR-like properties were shown by resveratrol treatment, with activation of AMPK and SIRT1 in the muscle biopsies (257). However, a larger trial demonstrated that resveratrol supplementation does not influence putative molecular targets of CR in postmenopausal women (258).

Epidemiological and clinical data on the benefits of curcumin are also growing. Curcumin appears well-tolerated and safe. Its poor bioavailability can be significantly increased by several dietary agents, such as piperine (a component from black pepper). Recently, a number of clinical trials and meta-analyses have aimed at summarizing the CR-like effects of curcumin on humans. Based on data from 8 RCTs, Hariri and Haghighatdoost systematically evaluated the evidence of the effects of curcumin supplementation on anthropometric measures, such as BMI, BW, WC, and fat mass. They found that curcumin, with a long duration of intervention, may reduce total body fat and visceral fat, but it was not enough to decrease BW and BMI significantly (259). Conversely, Akbari et al. pooled results from 21 clinical studies that comprised a total of 1,604 individuals and demonstrated that curcumin intake significantly decreased BMI, BW, and WC (260).

Although the lipid-lowering effects of curcumin remain inconclusive at this time, a meta-analysis of 7 randomized trials found a beneficial effect on total cholesterol and low-density lipoprotein cholesterol (LDL-C) in patients at risk of CVD. However, no significant effect was found with respect to serum high-density lipoprotein cholesterol (HDL-C) (261).

Of interest, curcumin could lower blood glucose concentrations of individuals with dysglycemia. A curcumin supplementation intervention in a pre-diabetic population improved overall function of $\beta$-cells and reduced the number of individuals who developed T2D (262). Likewise, it was observed that curcuminoid supplementation (i.e., curcumin, desmethoxycurcumin, and bisdemethoxycurcumin) decreased HbA1c and the homeostasis model assessment index for insulin resistance (HOMA-IR) in diabetic patients (263). These results were only confirmed for $\mathrm{HbAlc}$ in a metaanalysis of 11 studies (264). Curcumin has been also subject of intensive research because of its well-known anti-inflammatory properties. Intriguingly, it was observed that supplementation with curcumin reduces circulating concentrations of proinflammatory biomarkers and increases anti-inflammatory mediators irrespective of health status. Indeed, pooled from 32 trials showed a reduction in CRP, TNF- $\alpha$, IL- 6 , and an increase in IL-10 (265).

Flavan-3-ols, such as epicatechin and EGCG (also called catechins), have been extensively investigated for their role in human health and nutrition. The beneficial effect of flavan-3-ols 
is evident on cardiometabolic outcomes. Results from a metaanalysis of 156 RCTs suggest that flavan-3-ol intake has a positive effect on acute/chronic flow-mediated dilation (FMD), systolic (SBP) and diastolic blood pressure (DBP), total cholesterol, LDLC, HDL-C, TG, HbA1c, and HOMA-IR (266). Moreover, from the available meta-analyses, it was also reported that catechins have the propensity of reducing $\mathrm{BMI}, \mathrm{BW}$ and $\mathrm{WC}$, increasing metabolic rate even at low dose (ca. $300 \mathrm{mg}$ per day) (267269). However, current clinical data, recently meta-analyzed by Haghighatdoost and Hariri, do not suggest benefits of catechins on inflammatory mediators, such as CRP, TNF- $\alpha$, and IL-6 (270).

Quercetin is one of the most abundantly researched polyphenols. Several clinical trials evaluating the impact of quercetin supplementation on the prevention and treatment of chronic diseases have been completed. We retrieved 4 metaanalyses that covered data on lipid profile after quercetin supplementation (271-274). Although these analyses reported conflicting results on indices of lipid profile after quercetin treatment, it appears that changes in plasma lipids, in particular HDL-C and TG, are associated with quercetin dose (above 50 $\mathrm{mg} /$ day) and duration of supplementation (about 8 weeks). The current clinical evidence also suggests that quercetin intake does not affect BMI, BW, and WC (275). Conversely, the results of 4 meta-analysis showed a clear effect of quercetin supplementation in the reduction of BP and management of glucose-related parameters $(272,276,277)$. No relevant overall effects on inflammatory mediators were reported, except CRP in individuals with diagnosed diseases $(274,278)$.

As far as we know, there are no currently running or completed clinical trials evaluating the effects of the herein mentioned chalcones (4,4'-dimethoxychalcone, 3,4dimethoxychalcone, isobacachalcone). However, given the high interest in polyphenol-rich extracts and diets, it is likely that these compounds are present in some of the formulations tested in clinical studies.

\section{SALICYLIC ACID}

Salicylic and acetylsalicylic acid (also known as trademark Aspirin $^{\mathrm{TM}}$ ) have been in medical use for more than a century and qualify as CRMs, as they can induce autophagy and prolong lifespan of model organisms $(279,280)$. Of note, acetylsalicylic acid is rapidly converted to the more active form salicylate by blood and tissue hydrolases $(281,282)$. As a non-steroid, antiinflammatory, antimicrobial, antipyretic and analgesic drug, it possesses a high therapeutic potential. Many centuries before the synthetic production of aspirin was available, people made use of these properties by using willow bark as a natural source for salicylic acid. Since salicylic acids are central in plants as protective agents against various pathogens, it is constituent in various foods such as fruits, vegetables, spices, and herbs. Additionally, it is also used as a food preservative.

Daily intake varies greatly depending on different dietary habits (71). Major food sources include fruits, fruit juices, wines and vegetables. For instance, black- and blueberries contain roughly 0.8 and $0.6 \mathrm{mg} / \mathrm{kg}$, respectively, while nectarines contain more than $3 \mathrm{mg} / \mathrm{kg}$. Among vegetables, asparagus is rich in salicylates with up to $1.3 \mathrm{mg} / \mathrm{kg}$, as well as white onions with $0.8 \mathrm{mg} / \mathrm{kg}$ (72). Notably, foods containing a lot of spices show relevantly higher salicylate acid levels that can reach the amount of low dose Aspirin medication (283) if consumed in high amounts (for comparison: one standard tablet of Aspirin contains $75 \mathrm{mg}$ acetylsalicylic acid, a more tolerable derivative). For instance, cumin, paprika, thyme and mint contain 20-50 $\mathrm{mg} / \mathrm{kg}$ salicylate (72). Thus, it is suggested that diets rich in spices, such as south Indian menus, can contain daily levels of 12 $13 \mathrm{mg}$ (71). Large variations in the reported levels are present, as exemplified by salicylate levels in orange juice ranging from 0.47 to $3.02 \mathrm{mg}$ per liter (72). A systematic review of salicylates in foods of the Scottish population revealed an estimated intake of salicylates of 4.42 and $3.16 \mathrm{mg} /$ day for men and women, respectively (72). Another study calculated daily intake levels of $1.41 \mathrm{mg}$ (men) and $1.34 \mathrm{mg}$ (women) per day in a southern German cohort, with the major food sources being citrus fruits (30\%) and berries (24\%) (284).

\section{Salicylic Acid and Derivatives in Epidemiological and Clinical Studies}

Salicylic acid and derivatives (e.g., acetylsalicylic acid in Aspirin) in various commercial formulations have been in broadscale medical use for several decades, primarily for their antiinflammatory and analgesic properties. Aspirin inactivates cyclooxygenase- 1 and-2, leading to inhibition of prostaglandin synthesis. Accompanied by reduced platelet aggregation, this can also prevent and treat cardiovascular diseases. Released salicylic acid has a wide range of additional biological activities, including anti-inflammatory, -oxidant, and -proliferative properties.

More recently, long-term low- to middle-doses of Aspirin have gained attention as preventive strategies to promote health. Several clinical trials and meta-analyses thereof have been conducted. Regular Aspirin consumption has been associated with cardiovascular benefits and lower risk for cancers, especially of colorectal type (285-289). Evidence for the anticancer effects of aspirin and salicylates comes from both interventional, epidemiological and pre-clinical studies (290). Regarding prophylactic chemopreventive and cardioprotective actions, the cost-benefit profile of low-dose (75-325 mg/day) Aspirin consumption for at least 3 years seems to be largely in favor of Aspirin, although the potential gastrointestinal sideeffects must not be neglected $(291,292)$. At odds with several studies in younger cohorts, a recent large scale Australian and US study gave $100 \mathrm{mg}$ Aspirin to people over 70 and found no difference in overall cancer incidence after 4.7 years, while the risk of incident for late-stage and metastasized cancers was significantly elevated in the Aspirin group (293). This warrants caution for older age groups.

It has been suggested that the chemopreventive effects of aspirin consumption come from the salicylic acid formed in the body and that dietary salicylates could act similarly (290). In line with the higher amount of salicylates in plant-based foods, small-scale studies found that vegetarians have higher serum and urinary excretion levels than non-vegetarians, while average serum levels in vegetarians were only $11 \%$ of patients taking daily aspirin $(294,295)$. The authors found wide ranges and overlaps 
in the serum concentrations between vegetarians and aspirintreated patients, suggesting that it is possible to raise circulating salicylic acid levels by dietary means in some cases. Salicylate tissue levels could respond differently to dietary intake and it is yet unclear what role they play in the ascribed effects. Of note, similar to regular Aspirin consumption, vegetarianism and lowmeat diets have been associated with lowered cancer risk several times (296-298). However, studies by Janssen et al. suggest that the amount of acetylsalicylic acids in diets is probably too low to affect disease risk $(73,299)$. Thus, whether dietary salicylate consumption is sufficient to elicit disease-protecting activities remains debated.

Most trials indicating protective effects of aspirin against various diseases, use doses that likely exceed dietary intake levels by a magnitude of at least 10 and the required trials with doses achievable via the diet $(<15 \mathrm{mg} /$ day $)$ are currently absent. Hence, the accumulated effects of long-term and low-level dietary salicylate consumption remain elusive. However, it must be noted, that daily consumption of doses as low as $10 \mathrm{mg}$ have been reported to cause gastrointestinal complications, especially bleeding and ulcers, when consumed for more than a month (300, 301), highlighting the need for rigorous long-term, lowdose interventional studies that take into account dietary intake levels of salicylates.

\section{CONCLUSION AND PERSPECTIVE}

CR and different types of fasting are slowly approaching clinical applications, not only as weight management options $(12,302)$. These developments are accompanied by growing clinical interesting in the potential of naturally occurring and synthetic CRMs to ameliorate and treat diseases or support existing treatments, such as chemotherapy (303). Especially age-associated diseases and those with underlying autophagic disturbances will likely be priority targets. Natural CRM candidates are widely present in foods and, in most cases, inevitably consumed by humans. Given their prominent occurrence in plant-based foods (especially polyphenols and polyamines), it is conceivable that these compounds contribute to the beneficial effects of healthy diets. Nevertheless, to date, specific dietary recommendations must be read with caution as too many uncertainties remain regarding bioavailability, concentration in food, stability and optimal intake levels. Furthermore, estimations of CRM levels in healthy diet plans, such as the DASH, HEI-2010, AHEI-2010, or aMED, are largely elusive and should be evaluated in future studies, as they could add to or be responsible for some of the beneficial effects of these diets. Side by side with the herein discussed naturally occurring CRMs, other non-dietary substances also possess CR-mimicking properties. These prominently include rapamycin, metformin and synthetic sirtuin activators, among others, and are discussed elsewhere (20).

Overall, the promising and emerging field of dietary CRM candidates needs to be considered with scientific rigor, as large parts of evidence on their effects in humans come from epidemiological and/or small-scale studies, often conducted with plant-based extracts that contain numerous bioactive substances. Problems may also arise when translating preclinical and epidemiological evidence of dietary and bodyendogenous substances to clinical studies. For many of the herein discussed substances important data yet need to be collected: oral bioavailability, stability throughout the intestinal tract, metabolization, cellular uptake, distribution throughout the body, organ-specific effects, interaction with body-endogenous biosynthesis pathways and bioactive levels, just to name a few. More importantly, epidemiological data on dietary components can only be as good as the underlying food databases. Unfortunately, regionally varying food compositions, quality, the influence of meal preparation techniques and storage conditions are sometimes insufficiently studied or documented. Hence, deepened research into these questions is needed for the evolving field of dietary CRMs (and other dietary components). For dietary CRMs, different baseline intake levels likely influence outcomes of different dosing schemes. As an example, daily average spermidine intake levels are estimated to vary greatly between different countries (50), correlating with gross domestic product $(193,304)$, which might interfere with the effectiveness of doses near baseline dietary intake.

Finally, due to accumulating pre-clinical and clinical evidence, CRMs emerge as a prosperous future field of research that should be tackled in detail by clinical and nutrition researchers alike. Larger interventional studies are needed to validate first promising data from epidemiological and small-scale clinical trials. In terms of dietary CRMs, a detailed evaluation of existing food databases is warranted, and clinical trials should carefully take into account the dietary habits and food compositions of study cohorts. It will be interesting to see how the herein discussed compounds contribute to the beneficial effects of well-characterized healthy diets. Eventually, existing and newly developed healthy diet plans could be optimized with regards to levels of dietary CRM candidates.

\section{AUTHOR CONTRIBUTIONS}

$\mathrm{SH}$ and $\mathrm{SD}$ conceptualized the review. $\mathrm{SH}, \mathrm{SD}$, and $\mathrm{MB}$ wrote the manuscript. All authors provided critical feedback, edited, proof-read, and helped shape the review.

\section{FUNDING}

FM was grateful to the Austrian Science Fund FWF (SFB LIPOTOX F3007 and F3012, DK-MCD W1226, as well as Grant Nos. P29203, P29262, P27893, and P31727) and the Austrian Federal Ministry of Education, Science and Research, as well as the University of Graz for grants Unkonventionelle ForschungInterFast and Fast4Health, as well as flysleep(BMWFW-80.109/ 0001-WF/V/3b/2015). We acknowledge the support of the Field of Excellence BioHealth, of NAWI Graz and the BioTechMedGraz flagship project EPIAge.

\section{ACKNOWLEDGMENTS}

Figure 1 was created with BioRender.com. 


\section{REFERENCES}

1. Cena H, Calder PC. Defining a healthy diet: evidence for the role of contemporary dietary patterns in health and disease. Nutrients. (2020) 12:334. doi: 10.3390/nu12020334

2. Reedy J, Krebs-Smith SM, Miller PE, Liese AD, Kahle LL, Park Y, et al. Higher diet quality is associated with decreased risk of all-cause, cardiovascular disease, and cancer mortality among older adults12. J Nutr. (2014) 144:881889. doi: 10.3945/jn.113.189407

3. López-Otín C, Kroemer G. Hallmarks of Health. Cell. (2021) 184:3363. doi: 10.1016/j.cell.2020.11.034

4. Ridder D, de, Kroese F, Evers C, Adriaanse M, Gillebaart M. Healthy diet: health impact, prevalence, correlates, and interventions. Psychol Health. (2017) 32:907-41. doi: 10.1080/08870446.2017.1316849

5. Lee C, Longo V. Dietary restriction with and without caloric restriction for healthy aging. F1000Res. (2016) 5:117. doi: 10.12688/f1000research.7136.1

6. Longo VD, Antebi A, Bartke A, Barzilai N, Brown-Borg HM, Caruso C, et al. Interventions to slow aging in humans: are we ready? Aging Cell. (2015) 14:497-510. doi: 10.1111/acel.12338

7. Binh PNT, Soda K, Kawakami M. Mediterranean diet and polyamine intake: possible contribution of increased polyamine intake to inhibition of ageassociated disease. NDS. (2010) 3:1-7. doi: 10.2147/NDS.S15349

8. Davis C, Bryan J, Hodgson J, Murphy K. Definition of the mediterranean diet: a literature review. Nutrients. (2015) 7:9139-53. doi: 10.3390/nu7115459

9. Trichopoulou A, Vasilopoulou E. Mediterranean diet and longevity. $\mathrm{Br} \mathrm{J}$ Nutr. (2000) 84 (Suppl. 2):S205-9. doi: 10.1079/096582197388554

10. Hu FB, Willett WC. Optimal diets for prevention of coronary heart disease. JAMA. (2002) 288:2569-78. doi: 10.1001/jama.288.20.2569

11. Micha R, Peñalvo JL, Cudhea F, Imamura F, Rehm CD, Mozaffarian D. Association between dietary factors and mortality from heart disease, stroke, and type 2 diabetes in the United States. JAMA. (2017) 317:91224. doi: 10.1001/jama.2017.0947

12. de Cabo R, Mattson MP. Effects of intermittent fasting on health, aging, and disease. N Engl J Med. (2019) 381:2541-51. doi: 10.1056/NEJMra1905136

13. Francesco AD, Germanio CD, Bernier M, Cabo R. A time to fast. Science. (2018) 362:770-5. doi: 10.1126/science.aau2095

14. Stekovic S, Hofer SJ, Tripolt N, Aon MA, Royer P, Pein L, et al. Alternate day fasting improves physiological and molecular markers of aging in healthy, non-obese humans. Cell Metab. (2019) 30:46276.e5. doi: 10.1016/j.cmet.2019.07.016

15. Davinelli S, De Stefani D, De Vivo I, Scapagnini G. Polyphenols as caloric restriction mimetics regulating mitochondrial biogenesis and mitophagy. Trends Endocrinol Metab. (2020) 31:536-50. doi: 10.1016/j.tem.2020.02.011

16. Ingram DK, Roth GS. Glycolytic inhibition as a strategy for developing calorie restriction mimetics. Exp Gerontol. (2011) 46:148-54. doi: 10.1016/j.exger.2010.12.001

17. Ingram DK, Roth GS. Glycolytic inhibition: an effective strategy for developing calorie restriction mimetics. Geroscience. (2021) 43:115969. doi: 10.1007/s11357-020-00298-7

18. Ingram DK, Zhu M, Mamczarz J, Zou S, Lane MA, Roth GS, et al. Calorie restriction mimetics: an emerging research field. Aging Cell. (2006) 5:97108. doi: 10.1111/j.1474-9726.2006.00202.x

19. Madeo F, Pietrocola F, Eisenberg T, Kroemer G. Caloric restriction mimetics: towards a molecular definition. Nat Rev Drug Discov. (2014) 13:72740. doi: $10.1038 / \mathrm{nrd} 4391$

20. Madeo F, Carmona-Gutierrez D, Hofer SJ, Kroemer G. Caloric restriction mimetics against age-associated disease: targets, mechanisms, therapeutic potential. Cell Metab. (2019) 29:592-610. doi: 10.1016/j.cmet.2019. 01.018

21. Yin Z, Pascual C, Klionsky DJ. Autophagy: machinery and regulation. Microb Cell. (2016) 3:588-96. doi: 10.15698/mic2016.12.546

22. Eisenberg T, Schroeder S, Andryushkova A, Pendl T, Küttner V, Bhukel A, et al. Nucleocytosolic depletion of the energy metabolite acetyl-coenzyme a stimulates autophagy and prolongs lifespan. Cell Metab. (2014) 19:43144. doi: 10.1016/j.cmet.2014.02.010

23. Mariño G, Pietrocola F, Madeo F, Kroemer G. Caloric restriction mimetics: natural/physiological pharmacological autophagy inducers. Autophagy. (2014) 10:1879-82. doi: 10.4161/auto.36413
24. Mariño G, Pietrocola F, Eisenberg T, Kong Y, Malik SA, Andryushkova A, et al. Regulation of autophagy by cytosolic acetyl-coenzyme A. Mol Cell. (2014) 53:710-25. doi: 10.1016/j.molcel.2014.01.016

25. Madeo F, Zimmermann A, Maiuri MC, Kroemer G. Essential role for autophagy in life span extension. J Clin Invest. (2015) 125:8593. doi: 10.1172/JCI73946

26. Ohsumi Y. Historical landmarks of autophagy research. Cell Res. (2014) 24:9-23. doi: 10.1038/cr.2013.169

27. Vellai T, Takács-Vellai K, Sass M, Klionsky DJ. The regulation of aging: does autophagy underlie longevity? Trends Cell Biol. (2009) 19:48794. doi: 10.1016/j.tcb.2009.07.007

28. Yen WL, Klionsky DJ. How to live long and prosper: autophagy, mitochondria, and aging. Physiology. (2008) 23:24862. doi: 10.1152/physiol.00013.2008

29. Abdellatif M, Sedej S, Carmona-Gutierrez D, Madeo F, Kroemer G. Autophagy in cardiovascular aging. Circ Res. (2018) 123:80324. doi: 10.1161/CIRCRESAHA.118.312208

30. Abdellatif M, Ljubojevic-Holzer S, Madeo F, Sedej S. Autophagy in cardiovascular health and disease. Prog Mol Biol Transl Sci. (2020) 172:87106. doi: 10.1016/bs.pmbts.2020.04.022

31. Barbosa MC, Grosso RA, Fader CM. Hallmarks of aging: an autophagic perspective. Front Endocrinol. (2019) 9:790. doi: 10.3389/fendo.2018.00790

32. Park H, Kang JH, Lee S. Autophagy in neurodegenerative diseases: a hunter for aggregates. Int J Mol Sci. (2020) 21:3369. doi: 10.3390/ijms21093369

33. Eriau E, Paillet J, Kroemer G, Pol JG. Metabolic reprogramming by reduced calorie intake or pharmacological caloric restriction mimetics for improved cancer immunotherapy. Cancers. (2021) 13:1260. doi: 10.3390/cancers 13061260

34. Ingram DK, Roth GS. Calorie restriction mimetics: can you have your cake and eat it, too? Ageing Res Rev. (2015) 20:46-62. doi: 10.1016/j.arr.2014.11.005

35. Lee SH, Min KJ. Caloric restriction and its mimetics. BMB Rep. (2013) 46:181-7. doi: 10.5483/BMBRep.2013.46.4.033

36. Martel J, Chang SH, Wu CY, Peng H, Hwang TL, Ko YF, et al. Recent advances in the field of caloric restriction mimetics and anti-aging molecules. Ageing Res Rev. (2021) 66:101240. doi: 10.1016/j.arr.2020.101240

37. Riaz A, Rasul A, Hussain G, Zahoor MK, Jabeen F, Subhani Z, et al. Astragalin: a bioactive phytochemical with potential therapeutic activities. Adv Pharmacol Sci. (2018) 2018:9794625. doi: 10.1155/2018/9794625

38. Hossain A, Yamaguchi F, Matsuo T, Tsukamoto I, Toyoda Y, Ogawa M, et al. Rare sugar D-allulose: potential role and therapeutic monitoring in maintaining obesity and type 2 diabetes mellitus. Pharmacol Ther. (2015) 155:49-59. doi: 10.1016/j.pharmthera.2015.08.004

39. Naz S, Imran M, Rauf A, Orhan IE, Shariati MA, S.hahbaz M, et al. Chrysin: pharmacological and therapeutic properties. Life Sci. (2019) 235:116797. doi: 10.1016/j.lfs.2019.116797

40. Stompor-Goracy M, Bajek-Bil A, Machaczka M. Chrysin: perspectives on contemporary status and future possibilities as pro-health agent. Nutrients. (2021) 13:2038. doi: 10.3390/nu13062038

41. Spagnuolo C, Russo GL, Orhan IE, Habtemariam S, Daglia M, Sureda A, et al. Genistein and cancer: current status, challenges, future directions. Adv Nutr. (2015) 6:408-19. doi: 10.3945/an.114.008052

42. Hemati N, Asis M, Moradi S, Mollica A, Stefanucci A, Nikfar S, et al. Effects of genistein on blood pressure: a systematic review and meta-analysis. Food Res Int. (2020) 128:108764. doi: 10.1016/j.foodres.2019.108764

43. Polkowski K, Mazurek AP. Biological properties of genistein. A review of in vitro and in vivo data. Acta Pol Pharm. (2000) 57:135-55.

44. Tuli HS, Tuorkey MJ, Thakral F, Sak K, Kumar M, Sharma AK, et al. Molecular mechanisms of action of genistein in cancer: recent advances. Front Pharmacol. (2019) 10:1336. doi: 10.3389/fphar.2019.01336

45. Weimer S, Priebs J, Kuhlow D, Groth M, Priebe S, Mansfeld J, et al. D Glucosamine supplementation extends life span of nematodes and of ageing mice. Nat Commun. (2014) 5:3563. doi: 10.1038/ncomms4563

46. King DE, Xiang J. Glucosamine/Chondroitin and mortality in a US NHANES cohort. J Am Board Fam Med. (2020) 33:842-7. doi: 10.3122/jabfm.2020.06.200110

47. Li ZH, Gao X, Chung VC, Zhong WF, Fu Q, Lv YB, et al. Associations of regular glucosamine use with all-cause and cause-specific mortality: 
a large prospective cohort study. Ann Rheum Dis. (2020) 79:82936. doi: 10.1136/annrheumdis-2020-217176

48. Roth G, Hayek M, Massimino S, Davenport G, Arking R, Bartke A, et al. Mannoheptulose: glycolytic inhibitor and novel caloric restriction mimetic. FASEB J. (2009) 23:553.1. doi: 10.1096/fasebj.23.1_supplement.553.1

49. La Forge FB. Absorption and effect of ingested mannoheptulose. Nutr Rev. (1969) 27:206-8.

50. Madeo F, Hofer SJ, Pendl T, Bauer MA, Eisenberg T, Carmona-Gutierrez D, et al. Nutritional aspects of spermidine. Annu Rev Nutr. (2020) 40:13559. doi: 10.1146/annurev-nutr-120419-015419

51. Ramos-Molina B, Queipo-Ortuño MI, Lambertos A, Tinahones FJ, Peñafiel R. Dietary and gut microbiota polyamines in obesity- and age-related diseases. Front Nutr. (2019) 6:24. doi: 10.3389/fnut.2019.00024

52. Muñoz-Esparza NC, Latorre-Moratalla ML, Comas-Bast,é O, Toro-Funes $\mathrm{N}$, Veciana-Nogués MT, Vidal-Carou MC. Polyamines in food. Front Nutr. (2019) 6:108. doi: 10.3389/fnut.2019.00108

53. Atiya Ali M, Poortvliet E, Strömberg R, Yngve A. Polyamines in foods: development of a food database. Food Nutr Res. (2011) 55:5572. doi: 10.3402/fnr.v55i0.5572

54. Muñoz-Esparza NC, Costa-Catala J, Comas-Basté O, Toro-Funes N, LatorreMoratalla ML, Veciana-Nogués MT, et al. Occurrence of polyamines in foods and the influence of cooking processes. Foods. (2021) 10:1752. doi: $10.3390 /$ foods 10081752

55. Tjandrawinata RR. Dietary polyamines in Mediterranean diet and their health benefits. NDS. (2016) 8:85-6. doi: 10.2147/NDS.S116151

56. Pérez-Jiménez J, Neveu V, Vos F, Scalbert A. Systematic analysis of the content of 502 polyphenols in 452 foods and beverages: an application of the phenol-explorer database. J Agric Food Chem. (2010) 58:4959-69. doi: $10.1021 / \mathrm{jf} 100128 \mathrm{~b}$

57. Scalbert A, Williamson G. Dietary intake and bioavailability of polyphenols. J Nutr. (2000) 130:2073-85. doi: 10.1093/jn/130.8.2073S

58. Amalraj A, Pius A, Gopi S, Gopi S. Biological activities of curcuminoids, other biomolecules from turmeric and their derivatives - a review. J Tradit Complement Med. (2016) 7:205-33. doi: 10.1016/j.jtcme.2016.05.005

59. Kuhnle GGC. Nutrition epidemiology of flavan-3-ols: the known unknowns. Mol Aspects Med. (2018) 61:2-11. doi: 10.1016/j.mam.2017.10.003

60. Rothwell JA, Perez-Jimenez J, Neveu V, Medina-Remón A, M’Hiri N, GarcíaLobato P, et al. Phenol-Explorer 3.0: a major update of the phenol-explorer database to incorporate data on the effects of food processing on polyphenol content. Database. (2013) 2013:bat070. doi: 10.1093/database/bat070

61. Kahkeshani N, Farzaei F, Fotouhi M, Alavi SS, Bahramsoltani R, Naseri R, et al. Pharmacological effects of gallic acid in health and diseases: a mechanistic review. Iran J Basic Med Sci. (2019) 22:22537. doi: $10.22038 / \mathrm{ijbms} .2019 .32806 .7897$

62. Mah SH. Chalcones in diets. In: Xiao J, Sarker SD, Asakawa Y, editors. Handbook of Dietary Phytochemicals (Singapore: Springer). p. 1-52 (2019).

63. Teng H, Chen L. Polyphenols and bioavailability: an update. Crit Rev Food Sci Nutr. (2019) 59:2040-51. doi: 10.1080/10408398.2018.1437023

64. Ramírez-Garza SL, Laveriano-Santos EP, Marhuenda-Muñoz M, Storniolo CE, Tresserra-Rimbau A, Vallverdú-Queralt A, et al. Health effects of resveratrol: results from human intervention trials. Nutrients. (2018) 10:1892. doi: $10.3390 /$ nu10121892

65. Zamora-Ros R, Andres-Lacueva C, Lamuela-Raventós RM, Berenguer T, Jakszyn P, Martínez C, et al. Concentrations of resveratrol and derivatives in foods and estimation of dietary intake in a Spanish population: European prospective investigation into cancer and nutrition (EPIC)-Spain cohort. $\mathrm{Br}$ J Nutr. (2008) 100:188-96.

66. Semwal RB, Semwal DK, Vermaak I, Viljoen A. A comprehensive scientific overview of garcinia cambogia. Fitoterapia. (2015) 102:13448. doi: 10.1016/j.fitote.2015.02.012

67. Haber SL, Awwad O, Phillips A, Park AE, Pham TM. Garcinia cambogia for weight loss. Am J Health Syst Pharm. (2018) 75:1722. doi: 10.2146/ajhp160915

68. Da-Costa-Rocha I, Bonnlaender B, Sievers H, Pischel I, Heinrich M. Hibiscus sabdariffa L. A phytochemical and pharmacological review. Food Chem. (2014) 165:424-43. doi: 10.1016/j.foodchem.2014.05.002

69. Onakpoya I, Hung SK, Perry R, Wider B, Ernst E. The use of garcinia extract (hydroxycitric acid) as a weight loss supplement: a systematic review and meta-analysis of randomised clinical trials. J Obes. (2011) 2011:509038. doi: 10.1155/2011/509038

70. Márquez F, Babio N, Bulló M, Salas-Salvad,ó J. Evaluation of the safety and efficacy of hydroxycitric acid or garcinia cambogia extracts in humans. Crit Rev Food Sci Nutr. (2012) 52:585-94. doi: 10.1080/10408398.2010.500551

71. Duthie GG, Wood AD. Natural salicylates: foods, functions and disease prevention. Food Funct. (2011) 2:515-20. doi: 10.1039/c1fo10128e

72. Wood A, Baxter G, Thies F, Kyle J, Duthie G. A systematic review of salicylates in foods: estimated daily intake of a Scottish population. Mol Nutr Food Res. (2011) 55 (Suppl. 1):S7-14. doi: 10.1002/mnfr.201000408

73. Janssen PL, Katan MB, van Staveren WA, Hollman PC, Venema DP. Acetylsalicylate and salicylates in foods. Cancer Lett. (1997) 114:1634. doi: 10.1016/S0304-3835(97)04650-8

74. Elwood PC, Gallagher AM, Duthie GG, Mur LA, Morgan G. Aspirin, salicylates, and cancer. Lancet. (2009) 373:1301-9. doi: 10.1016/S0140-6736(09)60243-9

75. Bogan KL, Brenner C. Nicotinic acid, nicotinamide, and nicotinamide riboside: a molecular evaluation of $\mathrm{NAD}+$ precursor vitamins in human nutrition. Annu Rev Nutr. (2008) 28:115-30. doi: 10.1146/annurev.nutr.28.061807.155443

76. Institute of Medicine (US) Standing Committee on the Scientific Evaluation of Dietary Reference Intakes and its Panel on Folate, Other B Vitamins, and Choline. Dietary Reference Intakes for Thiamin, Riboflavin, Niacin, Vitamin B6, Folate, Vitamin B12, Pantothenic Acid, Biotin, and Choline. Washington, DC: National Academies Press (US); (1998) 6. Niacin.

77. Katsyuba E, Romani M, Hofer D, Auwerx J. NAD + homeostasis in health and disease. Nat Met. (2020) 2:9-31. doi: 10.1038/s42255-019-0161-5

78. Shintani T, Sakoguchi H, Yoshihara A, Izumori K, Sato M. d-Allulose, a stereoisomer of d-fructose, extends caenorhabditis elegans lifespan through a dietary restriction mechanism: a new candidate dietary restriction mimetic. Biochem Biophys Res Commun. (2017) 493:1528-33. doi: 10.1016/ j.bbrc.2017.09.147

79. Shintani H, Shintani T, Ashida H, Sato M. Calorie restriction mimetics: upstream-type compounds for modulating glucose metabolism. Nutrients. (2018) 10:1821. doi: 10.3390/nu10121821

80. Mu W, Zhang W, Feng Y, Jiang B, Zhou L. Recent advances on applications and biotechnological production of d-psicose. Appl Microbiol Biotechnol. (2012) 94:1461-7. doi: 10.1007/s00253-012-4093-1

81. Oshima H, Kimura I, Izumori K. Psicose contents in various food products and its origin. Food Sci Technol Res. (2006) 12:137-43. doi: $10.3136 /$ fstr.12.137

82. Shintani T, Kosuge Y, Ashida H. Glucosamine extends the lifespan of caenorhabditis elegans via autophagy induction. J Appl Glycosci. (2018) 65:37-43. doi: 10.5458/jag.jag.JAG-2018_002

83. Caramés B, Brinson D, Lotz M. Glucosamine regulates autophagy in vitro and in vivo. Osteoarthr Cartil. (2012) 20:S117-8. doi: 10.1016/j.joca. 2012.02.143

84. Shintani T, Yamazaki F, Katoh T, Umekawa M, Matahira Y, Hori S, et al. Glucosamine induces autophagy via an mTOR-independent pathway. Biochem Biophys Res Commun. (2010) 391:1775-9. doi: 10.1016/j.bbrc. 2009.12.154

85. Barrientos C, Racotta R, Quevedo L. Glucosamine attenuates increases of intraabdominal fat, serum leptin levels, and insulin resistance induced by a high-fat diet in rats. Nutr Res. (2010) 30:791-800. doi: $10.1016 /$ j.nutres.2010.10.008

86. Mohammadi M, Zamani A, Karimi K. Determination of glucosamine in fungal cell walls by high-performance liquid chromatography (HPLC). J. Agric. Food Chem. (2012) 60:10511-10515. doi: 10.1021/jf303488w

87. Nabavi SF, Braidy N, Habtemariam S, Orhan IE, Daglia M, Manayi A, et al. Neuroprotective effects of chrysin: from chemistry to medicine. Neurochem Int. (2015) 90:224-31. doi: 10.1016/j.neuint.2015.09.006

88. Pichichero E, Cicconi R, Mattei M, Muzi MG, Canini A. Acacia honey and chrysin reduce proliferation of melanoma cells through alterations in cell cycle progression. Int J Oncol. (2010) 37:973-81. doi: 10.3892/ijo_0000 0748

89. Mani R, Natesan V. Chrysin: sources, beneficial pharmacological activities, and molecular mechanism of action. Phytochemistry. (2018) 145:18796. doi: 10.1016/j.phytochem.2017.09.016 
90. Anandhi R, Annadurai T, Anitha TS, Muralidharan AR, Najmunnisha K, Nachiappan V, et al. Antihypercholesterolemic and antioxidative effects of an extract of the oyster mushroom, pleurotus ostreatus, and its major constituent, chrysin, in triton WR-1339-induced hypercholesterolemic rats. J Physiol Biochem. (2013) 69:313-23. doi: 10.1007/s13105-012-0215-6

91. Kalogeropoulos N, Yanni AE, Koutrotsios G, Aloupi M. Bioactive microconstituents and antioxidant properties of wild edible mushrooms from the island of Lesvos, Greece. Food Chem Toxicol. (2013) 55:37885. doi: 10.1016/j.fct.2013.01.010

92. Bhagwat S, Haytowitz DB, Holden JM. USDA Database for the Flavonoid Content of Selected Foods. Release 3.2 (November 2015). Nutrient Data Laboratory, Beltsville Human Nutrition Research Center, USDA (2016).

93. Lee SY, Lee S, Lee S, Oh JY, Jeon EJ, Ryu HS, et al. Primary and secondary metabolite profiling of doenjang, a fermented soybean paste during industrial processing. Food Chem. (2014) 165:157-66. doi: 10.1016/j.foodchem.2014.05.089

94. Quinhone A, Ida EI. Profile of the contents of different forms of soybean isoflavones and the effect of germination time on these compounds and the physical parameters in soybean sprouts. Food Chem. (2015) 166:1738. doi: 10.1016/j.foodchem.2014.06.012

95. van Erp-Baart MA, Brants HA, Kiely M, Mulligan A, Turrini A, Sermoneta $\mathrm{C}$, et al. Isoflavone intake in four different European countries: the VENUS approach. Br J Nutr. (2003) 89:S25-30. doi: 10.1079/BJN2002793

96. Messina $\mathrm{M}$, Nagata $\mathrm{C}$, Wu AH. Estimated asian adult soy protein and isoflavone intakes. Nutr Cancer. (2006) 55:112. doi: $10.1207 / \mathrm{s} 15327914$ nc5501_1

97. Dai W, Wang F, Lu J, Xia Y, He L, Chen $\mathrm{K}$, et al. By reducing hexokinase 2, resveratrol induces apoptosis in HCC cells addicted to aerobic glycolysis and inhibits tumor growth in mice. Oncotarget. (2015) 6:1370317. doi: 10.18632 /oncotarget. 3800

98. McKnight LL, Root-McCaig J, Wright D, Davenport GM, France J, Shoveller AK. Dietary mannoheptulose does not significantly alter daily energy expenditure in adult labrador retrievers. PLoS ONE. (2015) 10:e0143324. doi: 10.1371/journal.pone.0143324

99. Lane MA, Ingram DK, Roth GS. 2-Deoxy-D-Glucose feeding in rats mimics physiologic effects of calorie restriction. J Anti Aging Med. (1998) 1:32737. doi: 10.1089/rej.1.1998.1.327

100. Wan R, Camandola S, Mattson MP. Intermittent fasting and dietary supplementation with 2-deoxy-D-glucose improve functional and metabolic cardiovascular risk factors in rats. FASEB J. (2003) 17:1133-4. doi: 10.1096/fj.02-0996fje

101. Minor RK, Smith DL, Sossong AM, Kaushik S, Poosala S, Spangler EL, et al. Chronic ingestion of 2-deoxy-D-glucose induces cardiac vacuolization and increases mortality in rats. Toxicol Appl Pharmacol. (2010) 243:3329. doi: 10.1016/j.taap.2009.11.025

102. Zhu Z, Jiang W, McGinley JN, Thompson HJ. 2-Deoxyglucose as an energy restriction mimetic agent: effects on mammary carcinogenesis and on mammary tumor cell growth in vitro. Cancer Res. (2005) 65:702330. doi: 10.1158/0008-5472.CAN-05-0453

103. Schulz TJ, Zarse K, Voigt A, Urban N, Birringer M, Ristow $M$. Glucose restriction extends Caenorhabditis elegans life span by inducing mitochondrial respiration and increasing oxidative stress. Cell Metab. (2007) 6:280-93. doi: 10.1016/j.cmet.2007.08.011

104. Iida T, Hayashi N, Yamada T, Yoshikawa Y, Miyazato S, Kishimoto Y, et al. Failure of d-psicose absorbed in the small intestine to metabolize into energy and its low large intestinal fermentability in humans. Metabolism. (2010) 59:206-14. doi: 10.1016/j.metabol.2009.07.018

105. Iida T, Kishimoto Y, Yoshikawa Y, Hayashi N, Okuma K, Tohi M, et al. Acute D-psicose administration decreases the glycemic responses to an oral maltodextrin tolerance test in normal adults. J Nutr Sci Vitaminol. (2008) 54:511-4. doi: 10.3177/jnsv.54.511

106. Hayashi N, Iida T, Yamada T, Okuma K, Takehara I, Yamamoto T, et al. Study on the postprandial blood glucose suppression effect of D-psicose in borderline diabetes and the safety of long-term ingestion by normal human subjects. Biosci Biotechnol Biochem. (2010) 74:510-9. doi: 10.1271/bbb.90707

107. Kimura T, Kanasaki A, Hayashi N, Yamada T, Iida T, Nagata Y, et al. dAllulose enhances postprandial fat oxidation in healthy humans. Nutrition. (2017) 43-44:16-20. doi: 10.1016/j.nut.2017.06.007
108. Braunstein CR, Noronha JC, Glenn AJ, Viguiliouk E, Noseworthy R, Khan TA, et al. A double-blind, randomized controlled, acute feeding equivalence trial of small, catalytic doses of fructose and allulose on postprandial blood glucose metabolism in healthy participants: the fructose and allulose catalytic effects (FACE) trial. Nutrients. (2018) 10:E750. doi: 10.3390/nu10060750

109. Franchi F, Yaranov DM, Rollini F, Rivas A, Rivas Rios J, Been L, et al. Effects of D-allulose on glucose tolerance and insulin response to a standard oral sucrose load: results of a prospective, randomized, crossover study. BMJ Open Diabetes Res Care. (2021) 9:e001939. doi: 10.1136/bmjdrc-2020-001939

110. Noronha JC, Braunstein CR, Glenn AJ, Khan TA, Viguiliouk E, Noseworthy $\mathrm{R}$, et al. The effect of small doses of fructose and allulose on postprandial glucose metabolism in type 2 diabetes: a double-blind, randomized, controlled, acute feeding, equivalence trial. Diabetes Obes Metab. (2018) 20:2361-2370. doi: 10.1111/dom.13374

111. Han Y, Kwon EY, Yu MK, Lee SJ, Kim J, Kim SB, et al. A preliminary study for evaluating the dose-dependent effect of d-allulose for fat mass reduction in adult humans: a randomized, double-blind, placebo-controlled trial. Nutrients. (2018) 10:160. doi: 10.3390/nu10020160

112. Han Y, Choi BR, Kim SY, Kim SB, Kim YH, Kwon EY, et al. Gastrointestinal tolerance of d-allulose in healthy and young adults. A non-randomized controlled trial. Nutrients. (2018) 10:E2010. 10.3390/nu10122010

113. Qato DM, Alexander GC, Conti RM, Johnson M, Schumm P, Lindau ST. Use of prescription and over-the-counter medications and dietary supplements among older adults in the United States. JAMA. (2008) 300:2867-78. doi: 10.1001/jama.2008.892

114. Pocobelli G, Kristal AR, Patterson RE, Potter JD, Lampe JW, Kolar A, et al. Total mortality risk in relation to use of less-common dietary supplements. Am J Clin Nutr. (2010) 91:1791-800. doi: 10.3945/ajcn.2009.28639

115. Satia JA, Littman A, Slatore CG, Galanko JA, White E. Associations of herbal and specialty supplements with lung and colorectal cancer risk in the VITamins and lifestyle (VITAL) study. Cancer Epidemiol Biomarkers Prev. (2009) 18:1419-28. doi: 10.1158/1055-9965.EPI-09-0038

116. Bell GA, Kantor ED, Lampe JW, Shen DD, White E. Use of glucosamine and chondroitin in relation to mortality. Eur J Epidemiol. (2012) 27:593603. doi: 10.1007/s10654-012-9714-6

117. Navarro SL, White E, Kantor ED, Zhang Y, Rho J, Song X, et al. Randomized trial of glucosamine and chondroitin supplementation on inflammation and oxidative stress biomarkers and plasma proteomics profiles in healthy humans. PLoS ONE. (2015) 10:e0117534. doi: 10.1371/journal.pone.0117534

118. Xing D, Feng W, Nöt LG, Miller AP, Zhang Y, Chen F, et al. Increased protein O-GlcNAc modification inhibits inflammatory and neointimal responses to acute endoluminal arterial injury. Am J Physiol Heart Circ Physiol. (2008) 295:H335-42. doi: 10.1152/ajpheart.01259.2007

119. Kantor ED, Lampe JW, Vaughan TL, Peters U, Rehm CD, White E. Association between use of specialty dietary supplements and Creactive protein concentrations. Am J Epidemiol. (2012) 176:100213. doi: $10.1093 / \mathrm{aje} / \mathrm{kws} 186$

120. Lopes Júnior OV, Inácio AM. Use of glucosamine and chondroitin to treat osteoarthritis: a review of the literature. Rev Bras Ortop. (2013) 48:3006. doi: 10.1016/j.rbo.2012.09.007

121. McAlindon TE, LaValley MP, Gulin JP, Felson DT. Glucosamine and chondroitin for treatment of osteoarthritis: a systematic quality assessment and meta-analysis. JAMA. (2000) 283:146975. doi: 10.1001/jama.283.11.1469

122. Richy F, Bruyere O, Ethgen O, Cucherat M, Henrotin Y, Reginster, et al.Y. Structural and symptomatic efficacy of glucosamine and chondroitin in knee osteoarthritis: a comprehensive meta-analysis. Arch Intern Med. (2003) 163:1514-22. doi: 10.1001/archinte.163.13.1514

123. Simental-Mendía M, Sánchez-García A, Vilchez-Cavazos F, AcostaOlivo CA, Peña-Martínez VM, Simental-Mendía LE. Effect of glucosamine and chondroitin sulfate in symptomatic knee osteoarthritis: a systematic review and meta-analysis of randomized placebo-controlled trials. Rheumatol Int. (2018) 38:1413-28. doi: 10.1007/s00296-0184077-2

124. Singh JA, Noorbaloochi S, MacDonald R, Maxwell LJ. Chondroitin for osteoarthritis. Cochrane Database Syst Rev. (2015) 1:CD005614. doi: 10.1002/14651858.CD00561 4.pub2 
125. Zhu X, Sang L, Wu D, Rong J, Jiang L. Effectiveness and safety of glucosamine and chondroitin for the treatment of osteoarthritis: a meta-analysis of randomized controlled trials. J Orthop Surg Res. (2018) 13:170. doi: 10.1186/s13018-0180871-5

126. Egbuna C, Awuchi CG, Kushwaha G, Rudrapal M, Patrick-Iwuanyanwu $\mathrm{KC}$, Singh $\mathrm{O}$, et al. Bioactive compounds effective against type 2 diabetes mellitus: a systematic review. Curr Top Med Chem. (2021) 21. doi: $10.2174 / 1568026621666210509161059$

127. Mohammadi V, Dehghani S, Larijani B, Azadbakht L. Ovarian cancer risk and nonisoflavone flavonoids intake: a systematic review of epidemiological studies. J Res Med Sci. (2016) 21:123. doi: 10.4103/1735-1995.196605

128. Munhoz ACM, Frode TS. Isolated compounds from natural products with potential antidiabetic activity - a systematic review. Curr Diabetes Rev. (2018) 14:36-106. doi: 10.2174/1573399813666170505120621

129. Kwon HJ, Park YD. Determination of astragalin and astragaloside content in Radix Astragali using high-performance liquid chromatography coupled with pulsed amperometric detection. J Chromatogr A. (2012) 1232:2127. doi: 10.1016/j.chroma.2011.12.035

130. Tian H, Lu J, He H, Zhang L, Dong $\mathrm{Y}$, Yao $\mathrm{H}$, et al. The effect of astragalus as an adjuvant treatment in type 2 diabetes mellitus: a (preliminary) meta-analysis. J Ethnopharmacol. (2016) 191:206-15. doi: 10.1016/j.jep.2016.05.062

131. Xu D, Jin J, Yu H, Zhao Z, Ma D, Zhang C, et al. Chrysin inhibited tumor glycolysis and induced apoptosis in hepatocellular carcinoma by targeting hexokinase-2. J Exp Clin Cancer Res. (2017) 36:44. doi: 10.1186/s13046-017-0514-4

132. Walle T, Otake Y, Brubaker JA, Walle UK, Halushka PV. Disposition and metabolism of the flavonoid chrysin in normal volunteers. Br J Clin Pharmacol. (2001) 51:143-6. doi: 10.1111/j.1365-2125.2001.01317.x

133. Tobin PJ, Beale P, Noney L, Liddell S, Rivory LP, Clarke S. A pilot study on the safety of combining chrysin, a non-absorbable inducer of UGT1A1, and irinotecan (CPT-11) to treat metastatic colorectal cancer. Cancer Chemother Pharmacol. (2006) 57:309-16. doi: 10.1007/s00280-005-0053-0

134. Kwon SH, Kang MJ, Huh JS, Ha KW, Lee JR, Lee SK, et al. Comparison of oral bioavailability of genistein and genistin in rats. Int J Pharm. (2007) 337:148-54. doi: 10.1016/j.ijpharm.2006.12.046

135. Motlekar N, Khan MA, Youan BBC. Preparation and characterization of genistein containing poly(ethylene glycol) microparticles. J Appl Polym Sci. (2006) 101:2070-8. doi: 10.1002/app.23827

136. Sansai K, Na Takuathung M, Khatsri R, Teekachunhatean S, Hanprasertpong $\mathrm{N}$, Koonrungsesomboon N. Effects of isoflavone interventions on bone mineral density in postmenopausal women: a systematic review and metaanalysis of randomized controlled trials. Osteoporos Int. (2020) 31:185364. doi: 10.1007/s00198-020-05476-Z

137. Ding M, Pan A, Manson JE, Willett WC, Malik V, Rosner B, et al. Consumption of soy foods and isoflavones and risk of type 2 diabetes: a pooled analysis of three US cohorts. Eur J Clin Nutr. (2016) 70:13817. doi: 10.1038/ejcn.2016.117

138. Rienks J, Barbaresko J, Nöthlings U. Association of isoflavone biomarkers with risk of chronic disease and mortality: a systematic review and meta-analysis of observational studies. Nutr Rev. (2017) 75:616-41. doi: 10.1093/nutrit/nux021

139. Rienks J, Barbaresko J, Oluwagbemigun K, Schmid M, Nöthlings U. Polyphenol exposure and risk of type 2 diabetes: dose-response metaanalyses and systematic review of prospective cohort studies. Am J Clin Nutr. (2018) 108:49-61. doi: 10.1093/ajcn/nqy083

140. Yamada T, Hida H, Yamada Y. Chemistry, physiological properties, and microbial production of hydroxycitric acid. Appl Microbiol Biotechnol. (2007) 75:977-82. doi: 10.1007/s00253-007-0962-4

141. Preuss HG, Rao CVS, Garis R, Bramble JD, Ohia SE, Bagchi M, et al. An overview of the safety and efficacy of a novel, natural(-)-hydroxycitric acid extract (HCA-SX) for weight management. J Med. (2004) 35:33-48.

142. Louter-van de Haar J, Wielinga PY, Scheurink AJ, Nieuwenhuizen AG. Comparison of the effects of three different (-)-hydroxycitric acid preparations on food intake in rats. Nutr Metab. (2005) 2:23. doi: $10.1186 / 1743-7075-2-23$
143. Loe YC, Bergeron N, Rodriguez N, Schwarz JM. Gas chromatography/mass spectrometry method to quantify blood hydroxycitrate concentration. Anal Biochem. (2001) 292:148-54. doi: 10.1006/abio.200 1.5046

144. Hayamizu K, Ishii Y, Kaneko I, Shen M, Okuhara Y, Sakaguchi H, et al. No-observed-adverse-effect level(NOAEL) and sequential-high-doses administration study on garcinia cambogia extract in humans. J Oleo Sci. (2002) 51:365-9. doi: 10.5650/jos.51.365

145. Hayamizu K, Ishii Y, Shigematsu N, Okuhara Y, Tomi H, Furuse M, et al. Safety of Garcinia cambogia extract in healthy men: high-doses administration study I. J Oleo Sci. (2003) 52:499-504. doi: 10.5650/jos.52.499

146. Hayamizu K, Tomi H, Kaneko I, Shen M, Soni MG, Yoshino G. Effects of Garcinia cambogia extract on serum sex hormones in overweight subjects. Fitoterapia. (2008) 79:255-61. doi: 10.1016/j.fitote.2007.12.003

147. Ishii Y, Kaneko I, Shen M, Hayamizu K, Shigematsu N, Tomi H, et al. Safety of Garcinia cambogia extract in healthy volunteers: high-dose administration study II. J Oleo Sci. (2003) 52:663-71. doi: 10.5650/jos.52.663

148. Heymsfield SB, Allison DB, Vasselli JR, Pietrobelli A, Greenfield D, Nunez C. Garcinia cambogia (hydroxycitric acid) as a potential antiobesity agenta randomized controlled trial. JAMA. (1998) 280:1596-600. doi: 10.1001/jama.280.18.1596

149. Cheema-Dhadli S, Halperin ML, Leznoff CC. Inhibition of enzymes which interact with citrate by (-)Hydroxycitrate and 1,2,3,-Tricarboxybenzene. Euro J Biochem. (1973) 38:98-102. doi: 10.1111/j.1432-1033.1973.tb03038.x

150. Hayamizu K, Ishii Y, Kaneko I, Shen M, Okuhara Y, Shigematsu N, et al. Effects of garcinia cambogia (hydroxycitric acid) on visceral fat accumulation: a double-blind, randomized, placebo-controlled trial. Curr Ther Res Clin Exp. (2003) 64:551-67. doi: 10.1016/j.curtheres.2003.08.006

151. Roongpisuthipong C, Kantawan R, Roongpisuthipong W. Reduction of adipose tissue and body weight: effect of water soluble calcium hydroxycitrate in Garcinia atroviridis on the short term treatment of obese women in Thailand. Asia Pac J Clin Nutr. (2007) 16:25-9.

152. Clouatre DL, Preuss HG. Hydroxycitric acid does not promote inflammation or liver toxicity. World J Gastroenterol. (2013) 19:8160-2. doi: 10.3748/wjg.v19.i44.8160

153. Chi Y, Sauve AA. Nicotinamide riboside, a trace nutrient in foods, is a vitamin B3 with effects on energy metabolism and neuroprotection. Curr Opin Clin Nutr Metab Care. (2013) 16:657-61. doi: 10.1097/MCO.0b013e32836510c0

154. Abdellatif M, Trummer-Herbst V, Koser F, Durand S, Adão R, Vasques-Nóvoa F, et al. Nicotinamide for the treatment of heart failure with preserved ejection fraction. Sci Transl Med. (2021) 13:eabd7064. doi: 10.1126/scitranslmed.abd7064

155. Covarrubias AJ, Perrone R, Grozio A, Verdin E. NAD + metabolism and its roles in cellular processes during ageing. Nat Rev Mol Cell Biol. (2021) 22:119-41. doi: 10.1038/s41580-020-00313-x

156. Das A, Huang GX, Bonkowski MS, Longchamp A, Li C, Schultz $\mathrm{MB}$, et al. Impairment of an endothelial NAD+-H2S signaling network is a reversible cause of vascular aging. Cell. (2018) 173:74-89.e20. doi: 10.1016/j.cell.2018.02.008

157. Rajman L, Chwalek K, Sinclair DA. Therapeutic potential of NADboosting molecules: the in vivo evidence. Cell Metab. (2018) 27:52947. doi: 10.1016/j.cmet.2018.02.011

158. Schultz MB, Sinclair DA. Why NAD+ declines during aging: it's destroyed Cell Metab. (2016) 23:965-6. doi: 10.1016/j.cmet.2016.05.022

159. Bonkowski MS, Sinclair DA. Slowing ageing by design: the rise of NAD+ and sirtuin-activating compounds. Nat Rev Mol Cell Biol. (2016) 17:67990. doi: 10.1038/nrm.2016.93

160. Demarest TG, Babbar M, Okur MN, Dan X, Croteau DL, Fakouri NB, et al. NAD+ metabolism in aging and cancer. Ann Rev Cancer Biol. (2019) 3:105-30. doi: 10.1146/annurev-cancerbio-030518-055905

161. Fang EF, Lautrup S, Hou Y, Demarest TG, Croteau DL, Mattson MP, et al. NAD+ in aging: molecular mechanisms and translational implications. Trends Mol Med. (2017) 23:899-916. doi: 10.1016/j.molmed.2017.08.001

162. Igarashi M, Miura M, Williams E, Jaksch F, Kadowaki T, Yamauchi T, et al. $\mathrm{NAD}+$ supplementation rejuvenates aged gut adult stem cells. Aging Cell. (2019) 18:e12935. doi: 10.1111/acel.12935 
163. Ryu D, Zhang H, Ropelle ER, Sorrentino V, Mázala DAG, Mouchiroud $\mathrm{L}$, et al. NAD+ repletion improves muscle function in muscular dystrophy and counters global PARylation. Sci Transl Med. (2016) 8:361ra139. doi: 10.1126/scitranslmed.aaf5504

164. Zhang H, Ryu D, Wu Y, Gariani K, Wang X, Luan P, et al. NAD+ repletion improves mitochondrial and stem cell function and enhances life span in mice. Science. (2016) 352:1436-43. doi: 10.1126/science.aaf2693

165. Poljsak B, Kovač V, Milisav I. Healthy lifestyle recommendations: do the beneficial effects originate from NAD+ amount at the cellular level? Oxid Med Cell Longev. (2020) 2020:8819627. doi: 10.1155/2020/8819627

166. Institute of Medicine (US) Standing Committee on the Scientific Evaluation of Dietary Reference Intakes and its Panel on Folate, Other B Vitamins, and Choline. Dietary Reference Intakes for Thiamin, Riboflavin, Niacin, Vitamin B6, Folate, Vitamin B12, Pantothenic Acid, Biotin, and Choline. Washington, DC: National Academies Press (1998).

167. Bechgaard H, Jespersen S. GI absorption of niacin in humans. J Pharm Sci. (1977) 66:871-2. doi: 10.1002/jps.2600660635

168. Mills KF, Yoshida S, Stein LR, Grozio A, Kubota S, Sasaki Y, et al. Long-Term administration of nicotinamide mononucleotide mitigates ageassociated physiological decline in mice. Cell Metab. (2016) 24:795806. doi: 10.1016/j.cmet.2016.09.013

169. Goldberger J. The etiology of pellagra: the significance of certain epidemiological observations with respect thereto. Public Health Rep. (1914) 29:1683-6. doi: 10.2307/4570920

170. Carpenter KJ, Lewin WJ. A reexamination of the composition of diets associated with pellagra. J Nutr. (1985) 115:543-52. doi: 10.1093/jn/115.5.543

171. Airhart SE, Shireman LM, Risler LJ, Anderson GD, Gowda GAN, Raftery $\mathrm{D}$, et al. An open-label, non-randomized study of the pharmacokinetics of the nutritional supplement nicotinamide riboside (NR) and its effects on blood NAD+ levels in healthy volunteers. PLoS ONE. (2017) 12:e0186459. doi: 10.1371/journal.pone.0186459

172. Conze D, Brenner C, Kruger CL. Safety and metabolism of longterm administration of NIAGEN (nicotinamide riboside chloride) in a randomized, double-blind, placebo-controlled clinical trial of healthy overweight adults. Sci Rep. (2019) 9:9772. doi: 10.1038/s41598-019-46120-z

173. Dellinger RW, Santos SR, Morris M, Evans M, Alminana D, Guarente $\mathrm{L}$, et al. Repeat dose NRPT (nicotinamide riboside and pterostilbene) increases NAD + levels in humans safely and sustainably: a randomized, double-blind, placebo-controlled study. NPJ Aging Mech Dis. (2017) 3:179. doi: 10.1038/s41514-017-0016-9

174. Trammell SAJ, Schmidt MS, Weidemann BJ, Redpath P, Jaksch F, Dellinger RW, et al. Nicotinamide riboside is uniquely and orally bioavailable in mice and humans. Nat Commun. (2016) 7:12948. doi: 10.1038/ncomms12948

175. Phelan MJ. Phase II clinical trial of nicotinamide for the treatment of mild to moderate Alzheimer's disease. J Geriatr Med Gerontol. (2017) 3:2469. doi: 10.23937/2469-5858/1510021

176. Elhassan YS, Kluckova K, Fletcher RS, Schmidt MS, Garten A, Doig CL, et al. Nicotinamide riboside augments the aged human skeletal muscle NAD+ metabolome and induces transcriptomic and anti-inflammatory signatures. Cell Rep. (2019) 28:1717-28.e6. doi: 10.1016/j.celrep.2019.07.043

177. Dollerup OL, Trammell SAJ, Hartmann B, Holst JJ, Christensen B, Møller N, et al. Effects of nicotinamide riboside on endocrine pancreatic function and incretin hormones in nondiabetic men with obesity. J Clin Endocrinol Metab. (2019) 104:5703-5714. doi: 10.1210/jc.2019-01081

178. Martens CR, Denman BA, Mazzo MR, Armstrong ML, Reisdorph N, McQueen MB, et al. Chronic nicotinamide riboside supplementation is welltolerated and elevates NAD + in healthy middle-aged and older adults. Nat Commun. (2018) 9:1286. doi: 10.1038/s41467-018-03421-7

179. Garg A, Sharma A, Krishnamoorthy P, Garg J, Virmani D, Sharma T, et al. Role of niacin in current clinical practice: a systematic review. Am J Med. (2017) 130:173-87. doi: 10.1016/j.amjmed.2016.07.038

180. Takahashi Y, Tanaka A, Nakamura T, Fukuwatari T, Shibata K, Shimada N, et al. Nicotinamide suppresses hyperphosphatemia in hemodialysis patients. Kidney Int. (2004) 65:1099-104. doi: 10.1111/j.1523-1755.2004.00482.x

181. Pirinen E, Auranen M, Khan NA, Brilhante V, Urho N, Pessia A, et al. Niacin cures systemic NAD+ deficiency and improves muscle performance in adult-onset mitochondrial myopathy. Cell Metab. (2020) 31:107890.e5. doi: 10.1016/j.cmet.2020.04.008
182. Alisky JM. Niacin improved rigidity and bradykinesia in a Parkinson's disease patient but also caused unacceptable nightmares and skin rasha case report. Nutr Neurosci. (2005) 8:327-9. doi: 10.1080/10284150500 484638

183. Wakade C, Chong R, Bradley E, Morgan JC. Low-dose niacin supplementation modulates GPR109A, niacin index and ameliorates Parkinson's disease symptoms without side effects. Clin Case Rep. (2015) 3:635-7. doi: 10.1002/ccr3.232

184. Hellenbrand W, Boeing H, Robra BP, Seidler A, Vieregge P, Nischan P, et al. Diet and Parkinson's disease. II: A possible role for the past intake of specific nutrients. Results from a self-administered foodfrequency questionnaire in a case-control study. Neurology. (1996) 47:64450. doi: 10.1212/WNL.47.3.644

185. Madeo F, Eisenberg T, Pietrocola F, Kroemer G. Spermidine in health and disease. Science. (2018) 359:eaan2788. doi: 10.1126/science.an2788

186. Pegg AE. Mammalian polyamine metabolism and function. IUBMB Life. (2009) 61:880-94. doi: 10.1002/iub.230

187. Eisenberg T, Knauer H, Schauer A, Büttner S, Ruckenstuhl C, CarmonaGutierrez D, et al. Induction of autophagy by spermidine promotes longevity. Nat Cell Biol. (2009) 11:1305-14. doi: 10.1038/ncb1975

188. Eisenberg T, Abdellatif M, Schroeder S, Primessnig U, Stekovic S, Pendl $\mathrm{T}$, et al. Cardioprotection and lifespan extension by the natural polyamine spermidine. Nat Med. (2016) 22:1428-38. doi: 10.1038/nm.4222

189. Maglione M, Kochlamazashvili G, Eisenberg T, Rácz B, Michael E, Toppe D, et al. Spermidine protects from age-related synaptic alterations at hippocampal mossy fiber-CA3 synapses. Sci Rep. (2019) 9:19616. doi: 10.1038/s41598-019-56133-3

190. Schroeder S, Hofer SJ, Zimmermann A, Pechlaner R, Dammbrueck C, Pendl T, et al. Dietary spermidine improves cognitive function. Cell Rep. (2021) 35:108985. doi: 10.1016/j.celrep.2021.108985

191. Wirth A, Wolf B, Huang CK, Glage S, Hofer SJ, Bankstahi M, et al. Novel aspects of age-protection by spermidine supplementation are associated with preserved telomere length. GeroScience. (2021) 43:67390. doi: 10.1007/s11357-020-00310-0

192. Buyukuslu N, Hizli H, Esin K, Garipagaoglu M. A cross-sectional study: nutritional polyamines in frequently consumed foods of the turkish population. Foods. (2014) 3:541-57. doi: 10.3390/foods3040541

193. Binh PNT, Soda K, Kawakami M. Gross domestic product and dietary pattern among 49 western countries with a focus on polyamine intake. Health. (2010) 2:1327-34. doi: 10.4236/health.2010.211198

194. Zoumas-Morse C, Rock CL, Quintana EL, Neuhouser ML, Gerner EW, Meyskens FL. Development of a polyamine database for assessing dietary intake. J Am Diet Assoc. (2007) 107:1024-7. doi: 10.1016/j.jada.2007.03.012

195. Kiechl S, Pechlaner R, Willeit P, Notdurfter M, Paulweber B, Willeit $\mathrm{K}$, et al. Higher spermidine intake is linked to lower mortality: a prospective population-based study. Am J Clin Nutr. (2018) 108:37180. doi: 10.1093/ajcn/nqy102

196. Nishimura K, Shiina R, Kashiwagi K, Igarashi K. Decrease in polyamines with aging and their ingestion from food and drink. J Biochem. (2006) 139:81-90. doi: 10.1093/jb/mvj003

197. Soda K, Uemura T, Sanayama H, Igarashi K, Fukui T. Polyamine-rich diet elevates blood spermine levels and inhibits pro-inflammatory status: an interventional study. Med Sci. (2021) 9:22. doi: 10.3390/medsci9020022

198. Kiechl S, Willeit J. In a nutshell: findings from the bruneck study. Gerontology. (2019) 65:9-19. doi: 10.1159/000492329

199. Soda K, Kano Y, Chiba F. Food polyamine and cardiovascular disease -an epidemiological study. Glob J Health Sci. (2012) 4:p170. doi: 10.5539/gjhs.v4n6p170

200. Wirth M, Benson G, Schwarz C, Köbe T, Grittner U, Schmitz D, et al. The effect of spermidine on memory performance in older adults at risk for dementia: a randomized controlled trial. Cortex. (2018) 109:1818. doi: 10.1016/j.cortex.2018.09.014

201. Schwarz C, Stekovic S, Wirth M, Benson G, Royer P, Sigrist SJ, et al. Safety and tolerability of spermidine supplementation in mice and older adults with subjective cognitive decline. Aging. (2018) 10:1933. doi: 10.18632 /aging. 101354

202. Pekar T, Bruckner K, Pauschenwein-Frantsich S, Gschaider A, Oppliger M, Willesberger J, et al. The positive effect of spermidine in older adults suffering 
from dementia : first results of a 3-month trial. Wien Klin Wochenschr. (2021) 133:484-91. doi: 10.1007/s00508-020-01758-y

203. Matsumoto M, Kitada Y, Naito Y. Endothelial function is improved by inducing microbial polyamine production in the gut: a randomized placebo-controlled trial. Nutrients. (2019) 11:1188. doi: 10.3390/nu110 51188

204. Vargas AJ, Wertheim BC, Gerner EW, Thomson CA, Rock CL, Thompson PA. Dietary polyamine intake and risk of colorectal adenomatous polyps. Am J Clin Nutr. (2012) 96:133-41. doi: 10.3945/ajen.111.030353

205. Vargas AJ, Ashbeck EL, Wertheim BC, Wallace RB, Neuhouser ML, Thomson CA, et al. Dietary polyamine intake and colorectal cancer risk in postmenopausal women. Am J Clin Nutr. (2015) 102:4119. doi: 10.3945/ajen.114.103895

206. Ramot Y, Pietilä M, Giuliani G, Rinaldi F, Alhonen L, Paus R. Polyamines and hair: a couple in search of perfection. Exp. Dermatol. (2010) 19:78490. doi: 10.1111/j.1600-0625.2010.01111.x

207. Rinaldi F, Marzani B, Pinto D, Ramot Y. A spermidine-based nutritional supplement prolongs the anagen phase of hair follicles in humans: a randomized, placebo-controlled, double-blind study. Dermatol Pract Concept. (2017) 7:17-21. doi: 10.5826/dpc.0704a05

208. Vogt T. Phenylpropanoid biosynthesis. Mol Plant. (2010) 3:2-20. doi: $10.1093 / \mathrm{mp} / \mathrm{ssp} 106$

209. Tsao R. Chemistry and biochemistry of dietary polyphenols. Nutrients. (2010) 2:1231-46. doi: 10.3390/nu2121231

210. Haytowitz DB, Wu X, Bhagwat S. (2018) USDA Database for the Flavonoid Content of Selected Foods Release 3.3. U.S. Department of Agriculture, Agricultural Research Service. Nutrient Data Laboratory Home Page: http:// www.ars.usda.gov/nutrientdata/flav

211. Neveu V, Perez-Jimenez J, Vos F, Crespy V, du Chaffaut L, Mennen L, et al. Phenol-Explorer: an online comprehensive database on polyphenol contents in foods. Database. (2010) 2010:bap024. doi: 10.1093/database/bap024

212. Heimler D, Romani A, Ieri F. Plant polyphenol content, soil fertilization and agricultural management: a review. Euro Food Res Technol. (2017) 243:1107-15. doi: 10.1007/s00217-016-2826-6

213. Bhagwat S, Haytowitz DB, Wasswa-Kintu SI, Holden JM. USDA develops a database for flavonoids to assess dietary intakes. Proc Food Sci. (2013) 2:81-6. doi: 10.1016/j.profoo.2013.04.013

214. Tresserra-Rimbau A, Medina-Remón A, Pérez-Jiménez J, MartínezGonzález MA, Covas MI, Corella D, et al. Dietary intake and major food sources of polyphenols in a Spanish population at high cardiovascular risk: the PREDIMED study. Nutr Metab Cardiovasc Dis. (2013) 23:9539. doi: 10.1016/j.numecd.2012.10.008

215. Baur JA, Sinclair DA. Therapeutic potential of resveratrol: the in vivo evidence. Nat Rev Drug Discov. (2006) 5:493-506. doi: 10.1038/nrd2060

216. Zamora-Ros R, Andres-Lacueva C, Lamuela-Raventós RM, Berenguer T, Jakszyn P, Martínez C, et al. Concentrations of resveratrol and derivatives in foods and estimation of dietary intake in a Spanish population: European prospective investigation into cancer and nutrition (EPIC)-Spain cohort. $\mathrm{Br}$ J Nutr. (2008) 100:188-96. doi: 10.1017/S0007114507882997

217. Chachay VS, Kirkpatrick CMJ, Hickman IJ, Ferguson M, Prins JB, Martin JH. Resveratrol - pills to replace a healthy diet? Br J Clin Pharmacol. (2011) 72:27-38. doi: 10.1111/j.1365-2125.2011.03966.x

218. Ehala S, Vaher M, Kaljurand M. Characterization of phenolic profiles of Northern European berries by capillary electrophoresis and determination of their antioxidant activity. I Agric Food Chem. (2005) 53:648490. doi: $10.1021 / \mathrm{jf} 050397 \mathrm{w}$

219. Lamikanra O, Grimm CC, Rodin J, Ben, Inyang ID. Hydroxylated stilbenes in selected American wines. J Agric Food Chem. (1996) 44:11115. doi: $10.1021 / \mathrm{jf} 950274 \mathrm{j}$

220. Jayaprakasha GK, Rao LJM, Sakariah KK. Improved HPLC method for the determination of curcumin, demethoxycurcumin, and bisdemethoxycurcumin. J Agric Food Chem. (2002) 50:366872. doi: $10.1021 / \mathrm{jf025506a}$

221. Suresh D, Manjunatha H, Srinivasan K. Effect of heat processing of spices on the concentrations of their bioactive principles: turmeric (Curcuma longa), red pepper (Capsicum annuum) and black pepper (Piper nigrum). J Food Composit Anal. (2007) 20:346-51. doi: 10.1016/j.jfca.2006. 10.002
222. Tayyem RF, Heath DD, Al-Delaimy WK, Rock CL. Curcumin content of turmeric and curry powders. Nutr Cancer. (2006) 55:126-31. doi: 10.1207/s15327914nc5502_2

223. Vogiatzoglou A, Heuer T, Mulligan A, Lentjes M, Luben R, Kuhnle G. Estimated dietary intakes and sources of flavanols in the German population (German national nutrition survey II). Eur J Nutr. (2013) 53:63543. doi: 10.1007/s00394-013-0572-0

224. Bai W, Wang C, Ren C. Intakes of total and individual flavonoids by US adults. Int J Food Sci Nutr. (2014) 65:920. doi: 10.3109/09637486.2013.832170

225. Hollman PC, Katan MB. Dietary flavonoids: intake, health effects and bioavailability. Food Chem Toxicol. (1999) 37:93742. doi: 10.1016/S0278-6915(99)00079-4

226. Ranka S, Gee JM, Biro L, Brett G, Saha S, Kroon P, et al. Development of a food frequency questionnaire for the assessment of quercetin and naringenin intake. Eur J Clin Nutr. (2008) 62:1131-8. doi: 10.1038/sj.ejcn.1602827

227. Yao Z, Gu Y, Zhang Q, Liu L, Meng G, Wu H, et al. Estimated daily quercetin intake and association with the prevalence of type 2 diabetes mellitus in Chinese adults. Eur J Nutr. (2019) 58:81930. doi: 10.1007/s00394-018-1713-2

228. Grosso G, Stepaniak U, Topor-Madry R, Szafraniec K, Pajak A. Estimated dietary intake and major food sources of polyphenols in the polish arm of the HAPIEE study. Nutrition. (2014) 30:1398-403. doi: 10.1016/j.nut.2014.04.012

229. Carmona-Gutierrez D, Zimmermann A, Kainz K, Pietrocola F, Chen G, Maglioni S, et al. The flavonoid 4,4'-dimethoxychalcone promotes autophagy-dependent longevity across species. Nat Commun. (2019) 10:651. doi: 10.1038/s41467-019-08555-w

230. Chen G, Xie W, Nah J, Sauvat A, Liu P, Pietrocola F, et al. 3,4Dimethoxychalcone induces autophagy through activation of the transcription factors TFE3 and TFEB. EMBO Mol Med. (2019) 11:e10469. doi: 10.15252/emmm.201910469

231. Zhang P, Zhai Y, Cregg J, Ang KKH, Arkin M, Kenyon C. Stress resistance screen in a human primary cell line identifies small molecules that affect aging pathways and extend caenorhabditis elegans' lifespan. G3 Genes Genomes Genet. (2020) 10:849-62. doi: 10.1534/g3.119.400618

232. Zimmermann A, Kainz K, Hofer SJ, Bauer MA, Schroeder S, Dengjel J, et al. 4,4'Dimethoxychalcone: a natural flavonoid that promotes health through autophagy-dependent and -independent effects. Autophagy. (2019) 15:16624. doi: 10.1080/15548627.2019.1632623

233. Zhang W, Chen H, Ding L, Gong J, Zhang M, Guo W, et al. Trojan horse delivery of 4,4'-dimethoxychalcone for parkinsonian neuroprotection. $A d v$ Sci. (2021) 8:2004555. doi: 10.1002/advs.202004555

234. Wu Q, Tian AL, Durand S, Aprahamian F, Nirmalathasan N, Xie $\mathrm{W}$, et al. Isobacachalcone induces autophagy and improves the outcome of immunogenic chemotherapy. Cell Death Dis. (2020) 11:1-16. doi: 10.1038/s41419-020-03226-x

235. Pounis G, Costanzo S, Bonaccio M, Di Castelnuovo A, De Curtis A, Ruggiero E, et al. Reduced mortality risk by a polyphenol-rich diet: an analysis from the moli-sani study. Nutrition. (2018) 48:87-95. doi: 10.1016/j.nut.2017.11.012

236. Rabassa M, Cherubini A, Zamora-Ros R, Urpi-Sarda M, Bandinelli S, Ferrucci L, et al. Low levels of a urinary biomarker of dietary polyphenol are associated with substantial cognitive decline over a 3-year period in older adults: the invecchiare in chianti study. J Am Geriatr Soc. (2015) 63:938-46. doi: 10.1111/jgs.13379

237. Asgary S, Karimi R, Momtaz S, Naseri R, Farzaei MH. Effect of resveratrol on metabolic syndrome components: a systematic review and meta-analysis. Rev Endocr Metab Disord. (2019) 20:173-86. doi: 10.1007/s11154-019-09494-z

238. Elgebaly A, Radwan IAI, AboElnas MM, Ibrahim HH, Eltoomy MFM, Atta AA, et al. Resveratrol supplementation in patients with non-alcoholic fatty liver disease: systematic review and meta-analysis. J Gastrointestin Liver Dis. (2017) 26:59-67. doi: 10.15403/jgld.2014.1121.261.ely

239. Mousavi SM, Milajerdi A, Sheikhi A, Kord-Varkaneh H, FeinleBisset C, Larijani B, et al. Resveratrol supplementation significantly influences obesity measures: a systematic review and dose-response meta-analysis of randomized controlled trials. Obes Rev. (2019) 20:487-98. doi: 10.1111/obr.12775 
240. Tabrizi R, Tamtaji OR, Lankarani KB, Akbari M, Dadgostar E, Dabbaghmanesh $\mathrm{MH}$, et al. The effects of resveratrol intake on weight loss: a systematic review and meta-analysis of randomized controlled trials. Crit Rev Food Sci Nutr. (2020) 60:375-90. doi: 10.1080/10408398.2018.1529654

241. Akbari M, Tamtaji OR, Lankarani KB, Tabrizi R, Dadgostar E, Haghighat $\mathrm{N}$, et al. The effects of resveratrol on lipid profiles and liver enzymes in patients with metabolic syndrome and related disorders: a systematic review and meta-analysis of randomized controlled trials. Lipids Health Dis. (2020) 19:25. doi: 10.1186/s12944-020-1198-x

242. Guo XF, Li JM, Tang J, Li D. Effects of resveratrol supplementation on risk factors of non-communicable diseases: a meta-analysis of randomized controlled trials. Crit Rev Food Sci Nutr. (2018) 58:301629. doi: 10.1080/10408398.2017.1349076

243. Haghighatdoost F, Hariri M. Effect of resveratrol on lipid profile: an updated systematic review and meta-analysis on randomized clinical trials. Pharmacol Res. (2018) 129:141-50. doi: 10.1016/j.phrs.2017.12.033

244. Hausenblas HA, Schoulda JA, Smoliga JM. Resveratrol treatment as an adjunct to pharmacological management in type 2 diabetes mellitussystematic review and meta-analysis. Mol Nutr Food Res. (2015) 59:14759. doi: 10.1002/mnfr.201400173

245. Sahebkar A, Serban C, Ursoniu S, Wong ND, Muntner P, Graham IM, et al. Lack of efficacy of resveratrol on C-reactive protein and selected cardiovascular risk factors-Results from a systematic review and metaanalysis of randomized controlled trials. Int J Cardiol. (2015) 189:4755. doi: 10.1016/j.ijcard.2015.04.008

246. Zhang C, Yuan W, Fang J, Wang W, He P, Lei J, et al. Efficacy of resveratrol supplementation against non-alcoholic fatty liver disease: a meta-analysis of placebo-controlled clinical trials. PLOS ONE. (2016) 11:e0161792. doi: 10.1371/journal.pone.0161792

247. Zhao H, Song A, Zhang Y, Shu L, Song G, Ma H. Effect of resveratrol on blood lipid levels in patients with type 2 diabetes: a systematic review and meta-analysis. Obesity. (2019) 27:94-102. doi: 10.1002/oby.22348

248. Liu K, Zhou R, Wang B, Mi, M.-T. Effect of resveratrol on glucose control and insulin sensitivity: a meta-analysis of 11 randomized controlled trials. Am J Clin Nutr. (2014) 99:1510-9. doi: 10.3945/ajcn.113.082024

249. Ferrucci L, Fabbri E. Inflammageing: chronic inflammation in ageing, cardiovascular disease, and frailty. Nat Rev Cardiol. (2018) 15:50522. doi: 10.1038/s41569-018-0064-2

250. Franceschi C, Garagnani P, Parini P, Giuliani C, Santoro A. Inflammaging: a new immune-metabolic viewpoint for age-related diseases. Nat Rev Endocrinol. (2018) 14:576-90. doi: 10.1038/s41574-018-0059-4

251. Fulop T, Larbi A, Dupuis G, Le Page A, Frost EH, Cohen AA, et al. Immunosenescence and inflamm-aging as two sides of the same coin: friends or foes? Front Immunol. (2018) 8:1960. doi: 10.3389/fimmu.2017.01960

252. Kirkwood KL. Inflammaging. Immunol Invest. (2018) 47:7703. doi: 10.1080/08820139.2018.1552392

253. Custodero C, Mankowski RT, Lee SA, Chen Z, Wu S, Manini TM, et al. Evidence-based nutritional and pharmacological interventions targeting chronic low-grade inflammation in middle-age and older adults: a systematic review and meta-analysis. Ageing Res Rev. (2018) 46:4259. doi: 10.1016/j.arr.2018.05.004

254. Haghighatdoost F, Hariri M. Can resveratrol supplement change inflammatory mediators? A systematic review and metaanalysis on randomized clinical trials. Eur J Clin Nutr. (2019) 73:345-55. doi: 10.1038/s41430-018-0253-4

255. Koushki M, Dashatan NA, Meshkani R. Effect of resveratrol supplementation on inflammatory markers: a systematic review and meta-analysis of randomized controlled trials. Clin Ther. (2018) 40:1180-92.e5. doi: 10.1016/j.clinthera.2018.05.015

256. Tabrizi R, Tamtaji OR, Lankarani KB, Mirhosseini N, Akbari M, Dadgostar $\mathrm{E}$, et al. The effects of resveratrol supplementation on biomarkers of inflammation and oxidative stress among patients with metabolic syndrome and related disorders: a systematic review and meta-analysis of randomized controlled trials. Food Funct. (2018) 9:6116-28. doi: 10.1039/C8FO01259H

257. Goh KP, Lee HY, Lau DP, Supaat W, Chan YH, Koh AFY. Effects of resveratrol in patients with type 2 diabetes mellitus on skeletal muscle SIRT1 expression and energy expenditure. Int J Sport Nutr Exerc Metab. (2014) 24:2-13. doi: 10.1123/ijsnem.2013-0045
258. Yoshino J, Conte C, Fontana L, Mittendorfer B, Imai S, Schechtman KB, et al. Resveratrol supplementation does not improve metabolic function in non-obese women with normal glucose tolerance. Cell Metab. (2012) 16:658-64. doi: 10.1016/j.cmet.2012.09.015

259. Hariri M, Haghighatdoost F. Effect of curcumin on anthropometric measures: a systematic review on randomized clinical trials. J Am Coll Nutr. (2018) 37:215-22. doi: 10.1080/07315724.2017.1392263

260. Akbari M, Lankarani KB, Tabrizi R, Ghayour-Mobarhan M, Peymani P, Ferns $G$, et al. The effects of curcumin on weight loss among patients with metabolic syndrome and related disorders: a systematic review and meta-analysis of randomized controlled trials. Front Pharmacol. (2019) 10:649. doi: 10.3389/fphar.2019.00649

261. Qin S, Huang L, Gong J, Shen S, Huang J, Ren H, et al. Efficacy and safety of turmeric and curcumin in lowering blood lipid levels in patients with cardiovascular risk factors: a meta-analysis of randomized controlled trials. Nutr J. (2017) 16:68. doi: 10.1186/s12937-017-0293-y

262. Chuengsamarn S, Rattanamongkolgul S, Luechapudiporn R, Phisalaphong C, Jirawatnotai S. Curcumin extract for prevention of type 2 diabetes. Diabetes Care. (2012) 35:2121-7. doi: 10.2337/dc12-0116

263. Na LX, Li Y, Pan HZ, Zhou L, Sun DJ, Meng M, et al. Curcuminoids exert glucose-lowering effect in type 2 diabetes by decreasing serum free fatty acids: a double-blind, placebo-controlled trial. Mol Nutr Food Res. (2013) 57:1569-77. doi: 10.1002/mnfr.201200131

264. de Melo ISV, Dos Santos AF, Bueno NB. Curcumin or combined curcuminoids are effective in lowering the fasting blood glucose concentrations of individuals with dysglycemia: systematic review and meta-analysis of randomized controlled trials. Pharmacol Res. (2018) 128:137-44. doi: 10.1016/j.phrs.2017.09.010

265. Ferguson JJA, Abbott KA, Garg ML. Anti-inflammatory effects of oral supplementation with curcumin: a systematic review and metaanalysis of randomized controlled trials. Nutr Rev. (2021) 79:1043-66. doi: 10.1093/nutrit/nuaa114

266. Raman G, Avendano EE, Chen S, Wang J, Matson J, Gayer B, et al. Dietary intakes of flavan-3-ols and cardiometabolic health: systematic review and meta-analysis of randomized trials and prospective cohort studies. Am J Clin Nutr. (2019) 110:1067-78. doi: 10.1093/ajcn/nqz178

267. Hursel R, Viechtbauer W, Westerterp-Plantenga MS. The effects of green tea on weight loss and weight maintenance: a meta-analysis. Int J Obes. (2009) 33:956-61. doi: 10.1038/ijo.2009.135

268. Kapoor MP, Sugita M, Fukuzawa Y, Okubo T. Physiological effects of epigallocatechin-3-gallate (EGCG) on energy expenditure for prospective fat oxidation in humans: a systematic review and meta-analysis. J Nutr Biochem. (2017) 43:1-10. doi: 10.1016/j.jnutbio.2016.10.013

269. Phung OJ, Baker WL, Matthews LJ, Lanosa M, Thorne A, Coleman CI. Effect of green tea catechins with or without caffeine on anthropometric measures: a systematic review and meta-analysis. Am J Clin Nutr. (2010) 91:73-81. doi: 10.3945/ajen.2009.28157

270. Haghighatdoost F, Hariri M. The effect of green tea on inflammatory mediators: a systematic review and meta-analysis of randomized clinical trials. Phytother Res. (2019) 33:2274-87. doi: 10.1002/ptr.6432

271. Guo W, Gong X, Li M. Quercetin actions on lipid profiles in overweight and obese individuals: a systematic review and meta-analysis. Curr Pharm Des. (2019) 25:3087-95. doi: 10.2174/1381612825666190829153552

272. Huang H, Liao D, Dong Y, Pu R. Effect of quercetin supplementation on plasma lipid profiles, blood pressure, and glucose levels: a systematic review and meta-analysis. Nutr Rev. (2020) 78:615-26. doi: 10.1093/nutrit/ nuz071

273. Sahebkar A. Effects of quercetin supplementation on lipid profile: a systematic review and meta-analysis of randomized controlled trials. Crit Rev Food Sci Nutr. (2017) 57:666-76. doi: 10.1080/10408398.2014.948609

274. Tabrizi R, Tamtaji OR, Mirhosseini N, Lankarani KB, Akbari M, Heydari ST, et al. The effects of quercetin supplementation on lipid profiles and inflammatory markers among patients with metabolic syndrome and related disorders: a systematic review and meta-analysis of randomized controlled trials. Crit Rev Food Sci Nutr. (2020) 60:185568. doi: 10.1080/10408398.2019.1604491

275. Huang $\mathrm{H}$, Liao D, Dong Y, Pu R. Clinical effectiveness of quercetin supplementation in the management of weight loss: a pooled analysis of 
randomized controlled trials. Diabetes Metab Syndr Obes. (2019) 12:55363. doi: 10.2147/DMSO.S199830

276. Ostadmohammadi V, Milajerdi A, Ayati E, Kolahdooz F, Asemi Z. Effects of quercetin supplementation on glycemic control among patients with metabolic syndrome and related disorders: a systematic review and metaanalysis of randomized controlled trials. Phytother Res. (2019) 33:133040. doi: 10.1002/ptr.6334

277. Serban MC, Sahebkar A, Zanchetti A, Mikhailidis DP, Howard G, Antal $D$, et al. Effects of quercetin on blood pressure: a systematic review and meta-analysis of randomized controlled trials. J Am Heart Assoc. (2016) 5:e02713. doi: 10.1161/JAHA.115.002713

278. Ou Q, Zheng Z, Zhao Y, Lin W. Impact of quercetin on systemic levels of inflammation: a meta-analysis of randomised controlled human trials. Int $J$ Food Sci Nutr. (2020) 71:152-63. doi: 10.1080/09637486.2019.1627515

279. Pietrocola F, Castoldi F, Markaki M, Lachkar S, Chen G, Enot DP, et al. Aspirin recapitulates features of caloric restriction. Cell Rep. (2018) 22:2395407. doi: 10.1016/j.celrep.2018.02.024

280. Strong R, Miller RA, Astle CM, Floyd RA, Flurkey K, Hensley KL, et al. Nordihydroguaiaretic acid and aspirin increase lifespan of genetically heterogeneous male mice. Aging Cell. (2008) 7:64150. doi: 10.1111/j.1474-9726.2008.00414.x

281. Basheer A, Kaur S. Mammalian tissue acetylsalicylic acid esterase(s): identification, distribution and discrimination from other esterases. $J$ Pharmacol Exp Ther. (1983) 226:589-94.

282. Costello PB, Caruana JA, Green FA. The relative roles of hydrolases of the erythrocyte and other tissues in controlling aspirin survival in vivo. Arthrit Rheumat. (1984) 27:422-6. doi: 10.1002/art.1780270409

283. Paterson JR, Srivastava R, Baxter GJ, Graham AB, Lawrence JR. Salicylic acid content of spices and its implications. J Agric Food Chem. (2006) 54:2891-6. doi: 10.1021/jf058158w

284. Radtke J, Linseisen J, Wolfram G. [Phenolic acid intake of adults in a Bavarian subgroup of the national food consumption survey]. Z Ernahrungswiss. (1998) 37:190-7. doi: 10.1007/s003940050016

285. Antithrombotic Trialists Collaboration, Baigent C, Blackwell L, Collins R, Emberson J, Godwin J, et al. Aspirin in the primary and secondary prevention of vascular disease: collaborative meta-analysis of individual participant data from randomised trials. Lancet. (2009) 373:1849-60. doi: 10.1016/S0140-6736(09)60503-1

286. Corley DA, Kerlikowske K, Verma R, Buffler P. Protective association of aspirin/NSAIDs and esophageal cancer: a systematic review and metaanalysis. Gastroenterology. (2003) 124:47-56. doi: 10.1053/gast.2003.50008

287. Cuzick J, Otto F, Baron JA, Brown PH, Burn J, Greenwald P, et al. Aspirin and non-steroidal anti-inflammatory drugs for cancer prevention: an international consensus statement. Lancet Oncol. (2009) 10:5017. doi: 10.1016/S1470-2045(09)70035-X

288. Raju N, Sobieraj-Teague M, Hirsh J, O'Donnell M, Eikelboom J. Effect of aspirin on mortality in the primary prevention of cardiovascular disease. Am J Med. (2011) 124:621-9. doi: 10.1016/j.amjmed.2011.01.018

289. Raju N, Sobieraj-Teague M, Bosch J, Eikelboom JW. Updated Meta-Analysis of aspirin in primary prevention of cardiovascular disease. Am J Med. (2016) 129:e35-6. doi: 10.1016/j.amjmed.2015.10.046

290. Paterson JR, Lawrence JR. Salicylic acid: a link between aspirin, diet and the prevention of colorectal cancer. QJM. (2001) 94:445448. doi: 10.1093/qjmed/94.8.445

291. Cuzick J, Thorat MA, Bosetti C, Brown PH, Burn J, Cook NR, et al. Estimates of benefits and harms of prophylactic use of aspirin in the general population. Ann Oncol. (2015) 26:47-57. doi: 10.1093/annonc/mdu225

292. Patrignani P, Patrono C. Aspirin and cancer. J Am Coll Cardiol. (2016) 68:967-76. doi: 10.1016/j.jacc.2016.05.083

293. McNeil JJ, Gibbs P, Orchard SG, Lockery JE, Bernstein WB, Cao Y, et al. Effect of aspirin on cancer incidence and mortality in older adults. J Natl Cancer Inst. (2021) 113:258-65. doi: 10.1093/jnci/djaa114
294. Blacklock CJ, Lawrence JR, Wiles D, Malcolm EA, Gibson IH, Kelly CJ, et al. Salicylic acid in the serum of subjects not taking aspirin. Comparison of salicylic acid concentrations in the serum of vegetarians, non-vegetarians, and patients taking low dose aspirin. J Clin Pathol. (2001) 54:553-5. doi: 10.1136/jcp.54.7.553

295. Lawrence JR, Peter R, Baxter GJ, Robson J, Graham AB, Paterson JR. Urinary excretion of salicyluric and salicylic acids by non-vegetarians, vegetarians, and patients taking low dose aspirin. J Clin Pathol. (2003) 56:651-3. doi: 10.1136/jcp.56.9.651

296. Gilsing AMJ, Schouten LJ, Goldbohm RA, Dagnelie PC, van den Brandt PA, Weijenberg MP. Vegetarianism, low meat consumption and the risk of colorectal cancer in a population based cohort study. Sci Rep. (2015) 5:13484. doi: 10.1038/srep13484

297. Lanou AJ, Svenson B. Reduced cancer risk in vegetarians: an analysis of recent reports. Cancer Manag Res. (2010) 3:1-8. doi: 10.2147/CMAR.S6910

298. Molina-Montes E, Salamanca-Fernández E, Garcia-Villanova B, Sánchez MJ. The impact of plant-based dietary patterns on cancerrelated outcomes: a rapid review and meta-analysis. Nutrients. (2020) 12:2010. doi: 10.3390/nu12072010

299. Janssen PL, Hollman PC, Reichman E, Venema DP, van Staveren WA, Katan MB. Urinary salicylate excretion in subjects eating a variety of diets shows that amounts of bioavailable salicylates in foods are low. Am J Clin Nutr. (1996) 64:743-47. doi: 10.1093/ajcn/64.5.743

300. Cryer B, Feldman M. Effects of very low dose daily, long-term aspirin therapy on gastric, duodenal, and rectal prostaglandin levels and on mucosal injury in healthy humans. Gastroenterology. (1999) 117:1725. doi: 10.1016/S0016-5085(99)70545-7

301. Yeomans ND, Lanas AI, Talley NJ, Thomson ABR, Daneshjoo R, Eriksson $B$, et al. Prevalence and incidence of gastroduodenal ulcers during treatment with vascular protective doses of aspirin. Aliment Pharmacol Ther. (2005) 22:795-801. doi: 10.1111/j.1365-2036.2005.02649.x

302. Most J, Tosti V, Redman LM, Fontana L. Calorie restriction in humans: an update. Ageing Res Rev. (2017) 39:36-45. doi: 10.1016/j.arr.2016.08.005

303. Pietrocola F, Pol J, Vacchelli E, Rao S, Enot DP, Baracco EE, et al. Caloric restriction mimetics enhance anticancer immunosurveillance. Cancer Cell. (2016) 30:147-60. doi: 10.1016/j.ccell.2016.05.016

304. Binh PNT, Soda K, Maruyama C, Kawakami M. Relationship between food polyamines and gross domestic product in association with longevity in Asian countries. Health. (2010) 2:1390-6. doi: 10.4236/health.2010. 212206

Conflict of Interest: FM has equity interest in and is advisor of TLL The Longevity Labs GmbH and Samsara Therapeutics.

The remaining authors declare that the research was conducted in the absence of any commercial or financial relationships that could be construed as a potential conflict of interest.

Publisher's Note: All claims expressed in this article are solely those of the authors and do not necessarily represent those of their affiliated organizations, or those of the publisher, the editors and the reviewers. Any product that may be evaluated in this article, or claim that may be made by its manufacturer, is not guaranteed or endorsed by the publisher.

Copyright $\odot 2021$ Hofer, Davinelli, Bergmann, Scapagnini and Madeo. This is an open-access article distributed under the terms of the Creative Commons Attribution License (CC BY). The use, distribution or reproduction in other forums is permitted, provided the original author(s) and the copyright owner(s) are credited and that the original publication in this journal is cited, in accordance with accepted academic practice. No use, distribution or reproduction is permitted which does not comply with these terms. 